\title{
I. Thermodynamic properties of air
}

\section{A. W. Witkowski}

To cite this article: A. W. Witkowski (1896) I. Thermodynamic properties of air, Philosophical Magazine Series 5, 42:254, 1-37, DOI: 10.1080/14786449608620887

To link to this article: http://dx.doi.org/10.1080/14786449608620887

$$
\text { 曲 Published online: } 08 \text { May } 2009 .
$$

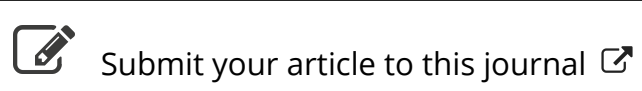

\footnotetext{
Џ Article views: 4
}

Q View related articles $\asymp$ 
TH E

LONDON, EDINBURGH, AND DUBLIN

PHILOSOPHICAL MAGAZINE

AND

JOURNAL OF SCIENCE.

[FIFTH SERIES.]

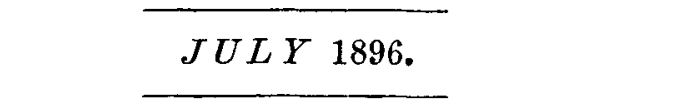

I. Thermodynamic Properties of Air.

By A. W. W itkowski.

[Plates I. \& II.]

Part II.*

Specific Heat.

$\S 1$. $\mathrm{N}$ order to obtain a full knowledge of the thermo1 dynamic properties of a homogeneous gaseous substance it is indispensable to perform upon it a twofold experimental investigation: besides its thermometric and dynamic behaviour the calorimetric properties ought to be studied independently. It is known that, in order to solve the first part of the problem, it is sufficient to test the thermal expansion of the gas under different pressures and its compressibility at one temperature-or conversely, the compressibility at different temperatures, together with the expansion under a single pressure. This part of the problem I worked out experimentally four years ago ; the results have been published in the 23rd volume of the Rozprawy. In the present papsr I intend to supplement these investigations by the second, calorimetric part.

In this respect we may make use of the general laws of

* Translated from the 32nd volume (1896) of the "Rozprawy" of the Cracow Academy of Science (Math. Class) and communicated by the Author. For Part I., see p. 288, vol. xli.

Phil. Mag. S. 5. Vol. 42. No. 254. July 1896. 
thermodynamics. It follows that, in order to disclose the whole of the calorimetric properties of a homogeneous fluid, it is sufficient to investigate experimentally the specific hea', in its dependence on temperature, under a single constant pressure, together with its comprossibility and thermal expansion.

\$2. Any state of thermodynamic equilibrium of the gas may be defined by means of two independent variables, for instance by its pressure $p$, and temperature $\theta(=t$ on the absolute thermodynamic scale). Consider an infinitely small change of state, corresponding to the increments $d p$ and $d t$ of the variables; then the gas does a quantity of work,

$$
d \mathrm{~L}=p \frac{\partial v}{\partial t} d t+p \frac{\partial v}{\partial p} d p
$$

and absorbs a quantity of heat,

$$
d \mathrm{Q}=m c_{p} d t+l d p \text {. }
$$

We denote by $m$ the mass of the fluid, by $c_{p}$ its specific heat under the constant pressure $p$, by $l$ a certain kind of latent heat; the last two quantities are to be considered as variables, depending on $p$ and $t$.

The four coefficients $\frac{\partial v}{\partial t}, \frac{\partial v}{\partial p}$ (thermal expansion and compressibility), $c_{p}$, and $l$, when known for every state $(p, t)$ of the body, give a full account of its thermodynamic properties, They are not independent; by the general laws of thermodynamics they are subject to the relations

$$
l=-\frac{t}{J} \frac{\partial v}{\partial t} ; \frac{\partial c_{p}}{\partial p}=-\frac{t}{J m} \frac{\partial^{2} v}{\partial t^{2}} ; . . . .
$$

where $\mathbf{J}$ denotes the dynamical equivalent of the heat-unit.

Amongst other thermodynamic properties we have to consider, in the first place, the specific heat at constant volume $=c_{v}$. It may be expressed in terms of the above coefficients by the known equation

or else by

$$
c_{v}=c_{p}+\frac{t}{J m} \frac{\left(\frac{\partial p}{\partial t}\right)^{2}}{\frac{\partial p}{\partial v}} ; \quad . \quad . \quad . \quad .
$$

$$
\frac{\partial c_{v}}{\partial v}=\frac{t}{\mathrm{~J} m} \frac{\partial^{2} p}{\partial t^{2}} \ldots . ., \ldots . . .
$$

It follows from these equations, that the variations of the 
specific heats, as well as their difference, can be deduced from the fundamental equation of the body, viz. $v=\mathrm{F}(p, t)$. Although we do not possess a sufficiently accurate general expression for the volume of atmospheric air in terms of the pressure and temperature, yet some inferences as to the thermodynamic behaviour of that body at different temperatures, down to the critical, and under different pressures, may be drawn from the numerical data which have been given in the first part of the present paper, both in tabular and in graphical form. These results can be obtained by means of the graphical calculus. It is true that results arrived at in this manner cannot be as accurate and convincing as those obtained by direct experiment. Still I thought them worthy of attention, the more so as direct calorimetric measurements at very low temperatures would be attended by serious difficulties. Another reason which induced me to try the indirect method was the desire to learn something more about the specific heat of gases, which has been investigated nsually only within very restricted limits of temperature and pressure. Besides the important work of Prof. Joly*, the object of which was to determine the effects of increased pressure and temperature on the specific heat at constant volume, I have to notice a memoir by M. Margules $\dagger$ on the variations of the specific heat of carbon dioxide, determined by calculations based on Andrews's and Amagat's experiments.

$\S 3$. Integrating (1) along the isothermal $t$, between the limits of 1 and $p$ atmospheres we obtain

$$
c_{p}=c_{1}-\frac{t}{J m} \int_{1}^{p} \frac{\partial^{2} v}{\partial t^{2}} d p
$$

If we assume the thermal expansion to be known, this equation (Rankine's) may be used to calculate the values of $c_{p}$ corresponding to different states of the gas.

First of all, however, it is necessary to inquire how far the quantity $c_{1}-\mathrm{a}$ constant of integration with respect to $p-$ depends on the temperature; $c_{1}$ denotes evidently the specific heat under the constant pressure of one atmosphere, at the absolute temperature $t$.

In order not to depart from the notation adopted in the first part, I shall denote by $p$ the pressure expressed in atmospheres. The mass $m$ of the gas may be chosen so as to have $v=1$ cubic centim. at the temperature of melting ice, under

* "Specific Heats of Gases at Constant Volume," Phil. Trans. part i., vol. clxxxii. (1891); part ii. vol. clxxxv. (1894); part iii. vol. clxxxv. (1894).

† "Spezifische Wärme der comprimirten Kohlensäure," Wien. Sitzber. xcvii. Ila., 1888. 
the pressure of one atmosphere $\left(1033 \cdot 24 \frac{\mathrm{gr}}{\mathrm{cm}^{2}}\right)$; thus it follows that $m=0.001293$ grammes. Assuming, further, $\mathrm{J}=42,700$ gramme-centimetres per gramme-calorie, the last equation becomes

$$
c_{p}=c_{1}-18 \cdot 714 t \int_{1}^{p} \frac{\partial^{2} v}{\partial t^{2}} d p . \quad \text {. . . . }
$$

Similarly, instead of (2) we obtain

$$
c_{v}=c_{p}+18.714 t \frac{\left(\frac{\partial p}{\partial t}\right)^{2}}{\frac{\partial p}{\partial v}} . . . . .
$$

$\S 4$. It has been already remarked that the investigation onght to bear in the first place on the quantity $c_{1}$. The specific heat of atmospheric air under constant pressure has been repeatedly measured. In the first rank there stands the fundamental work of Regnault*; fourteen years later these experiments were repeated by $\mathrm{E}$. Wiedemannt, with the help of a simpler form of apparatus. Regnault's experiments cover a range of temperature from $+200^{\circ}$ to $-31^{\circ}$; air of ordinary density was tried, as well as condensed air, up to 12 atmospheres. Notwithstanding these relatively extended limits Regnault was not able to discover any marked variation of the quantity $c_{p}$; hence there arose the very general belief, that the specific beat of air is a constant, independent of pressure and temperature--an opinion which, as will be seen further on, is very far from being correct. Wiedemann's experiments, so fur as air is concerned, were intended to control Regnault's value of the specific heat. The results obtained by the two investigators are only in approximate agreement. According to Regnault the most probable value of the specific heat $c_{1}$ between $0^{\circ}$ and $+100^{\circ}$ is 0.23741 ; this is the mean value of single determinations varying between the limits $0 \cdot 23536$ and 0.23890 .

Wiedemann's result is 0.2389 , the limits of single determinations being 0.2374 and $0 \cdot 2414$. Although the principal aim of my own experiments was to find the variations of the specific heat of air through as wide a range of temperatures as possible, yet $I$ thought it worth while to redetermine once more the exact value of this important constant; this seemed

* Relation des expériences \&c., tome ii. pp. 41-110, an 1 pp. 206-224. (Paris, 1862.)

† "Spez. Wärme des Gase," Pogg. Ann. vol. clvii. (1876), pp. 19-22. 
the more desirable, as the thermometric scale is now better defined, thanks to the investigations of the International Bureau of Weights and Measures-and some light has also been thrown on the variations of the specific heat of water. I may mention now that my result, as regards the specific heat of air, is nearly identical with that of Regnault.

To detect any variations in the specific heat of air at atmospheric pressure it was desirable to enlarge the limits of the experiments on the side of low temperatures, because on the ground of Regnault's work we may be sure that at high temperatures such variations do not manifest themselves; in this respect I have been able to reach the temperature of $-170^{\circ}$.

\$5. In order to adapt the well-known apparatus employed usually to determine the specific heat of gasas to the particular problem of low-temperature calorimetry it was necessary to to modify it in several respects. I wished also to make it more reliable, so as to lessen as far as possible the limits of experimental errors, because of the smalness of the expected variations in the specific heat.

In studying Regnault's memoir on the specific heat of gases, one comes to the conclusion that the chief cause of error in determinations of this kind is to be sought in the uncertainty as regards the true temperature of the gas at the moment when it enters the calorimeter, $i . e$. the cooier immersed in it. The influence of this cause of error manifests itself clearly by the fact that the calculated value of the specific heat depends in a marked degree on the velocity with which the gas-stream is made to pass through the apparatus : on increasing this velocity the result tends towards a maximum value. It is known thiat Regnault considered only those determinations as valid which corresponded to this maximum.

In my own experiments I used at first an apparatus similar to that of $\mathrm{E}$. Wiedemann $(l . c$.$) . I soon became convinced$ that in order to do away with the uncertainty as to the initial temperature of the gas, and at the same time to diminish as far as possible the direct influx of heat (or cold) from the heating apparatus into the calorimeter, it was indispensable to improve the mode of connexion of these two parts. The following conditions were to be kept in view in devising this most important part of the apparatus :- (1) The connecting piece ought to be perfectly air-tight, and at the same time a bad conductor of heat; (2) it ought to transfer the gas from the heater into the calorimeter with the least possible loss of heat; (3) some thermometric arrangement ought to be introduced in it in order to measure directly the temperature of the gas-stream where it enters the calorimeter. 
It is known that the determination of the temperature of a gas is attended by some difficulty. Owing to the great diathermancy of these bodies, a thermometer introduced in a gas tends to show rather the temperature of the surrounding bodies than of the gas itself. To get over this difficulty I resolved to apply a mode of temperature-measurement which has proved successful in meteorological observations, and is perhaps best known in its application in Assmann's aspirating thermometer. The thermometer is placed inside a polished metal tube, through which a brisk current of air is made to pass. It has been fonnd that under such conditions the temperature indicated is nearly independent of the temperature of the tube. After several trials $I$ constructed upon this principle the connexion between the heater and the calorimeter; it will be described fully in $\$ 7$. The only thermometric apparatus which could be applied under the given conditions was the thermo-electric couple. The mode of experimenting was such that, instead of measuring the initial temperature of the gas, I determined with the aid of the couple only the small loss of temperature experienced by the gas during its passage from the heater into the calorimeter. For this purpose one of the solderings of the couple was placed in the gas-stream, just inside the calorimeter, the other in the heater, or in a separate thermostat of known temperature. This second soldering was always in contact with the bulb of a hydrogen thermometer, in order to reduce finally the observed temperatures to a definite scale.

$\S 6$. Another modification concerned the determination of the mass of air used in every calorimetric experiment. Usually the quantity of gas has been determined by previous experimenters in an indirect way. E. Wiedemann, following Delaroche and Bérard, measured the volume of water which replaced the gas, contained initially in a bladder or indiarubber bag. Regnault used a spacious receiver filled with compressed gas, and observed the fall of pressure occasioned by the using up of gas in every experiment. The volume of the receiver and its temperature being known, the mass could be calculated on the basis of the law of compressibility, which Regnault determined himself expressly for that purpose. I have found it more convenient and accurate to measure the mass of air by direct weighing. Accordingly a large reservoir (about ten litres capacity) was filled with pure compre:sed air at a pressure of 80-100 atmospheres : this was ample enough to provide the gas for some dozen of calorimetric determinations. From this store I filled small metal flasks (capacities 136, 220, 208 cubic centim.), as 
represented in fig. 1, provided with screw stopcocks. These were weighed on a large chemical balance carrying some 1500 grammes. By gradually opening the stopcocks the flasks yielded during the calorimetric experiment a perfectly uniform current of air. They were then again weighed, whence, by applying the usual corrections, the mass of gas passed through the calorimeter could be accurately calculated. In the three flasks used it was easy to store up some 50 or 60 litres of gas. The tightness of the flasks and stopcocks was controlled by the weighings themselves; even a small leakage renders an accurate weighing impossible *.

The mode of preparing and compressing the air was exactly the same as described in Part I., $\$ 5$.

$\$ 7$. I shall now describe the calorimetric apparatus, namely that form of it which I used in the low-temperature work. In my first experiments I constructed a calorimeter on the lines of that of Fig. 1.

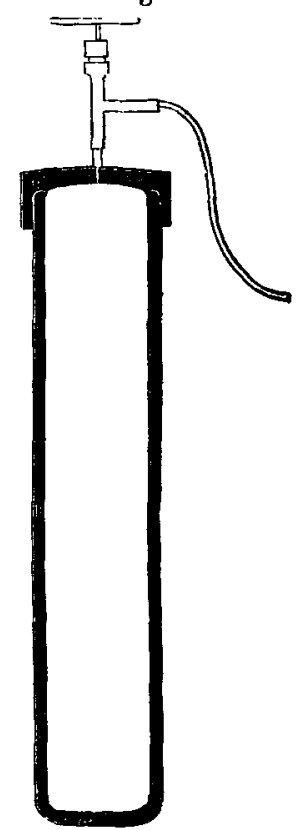
Regnault and Wiedemann; the cooler, i. e. the system of metallic tubes destined to transmit heat from the gas to the water, was attached to the calorimetric vessel by solder, while the exit-tube of the heater was introduced near the bottom of the vessel and fixed there by means of a cork. This arrangement proved inconvenient, and moreover it rendered difficult the intended measurement of the initial temperature of the gas. Accordingly I modified the apparatus in such a manner as to make the beater entirely independent of the calorimeter proper. In fig. 2 (reduced in the ratio $2 \frac{1}{2}: 1$ ) $\mathrm{DPR}^{\prime} \mathrm{R}$ represents the heater ( $\mathrm{I}$ shall continue to call it so, although, when used at low' temperatures, it acts really as a cooler); $S$ the cooler; both are fixed to a separate support $\mathrm{E}$, which stands on a heavy base $\mathrm{E}^{\prime}$. This part of the apparatus may thus be used in conjunction with different calorimetric vessels.

* I think that the method described here, of weighing gases in a compressed condition, could be advantageously employed in accurate determinations of the density of some gases under atmospheric pressure. For that purpose the weighed flasks ought to be discharged into an empty receiver of known capacity and temperature, provided with a mercury manometer. 
Fig. 2.
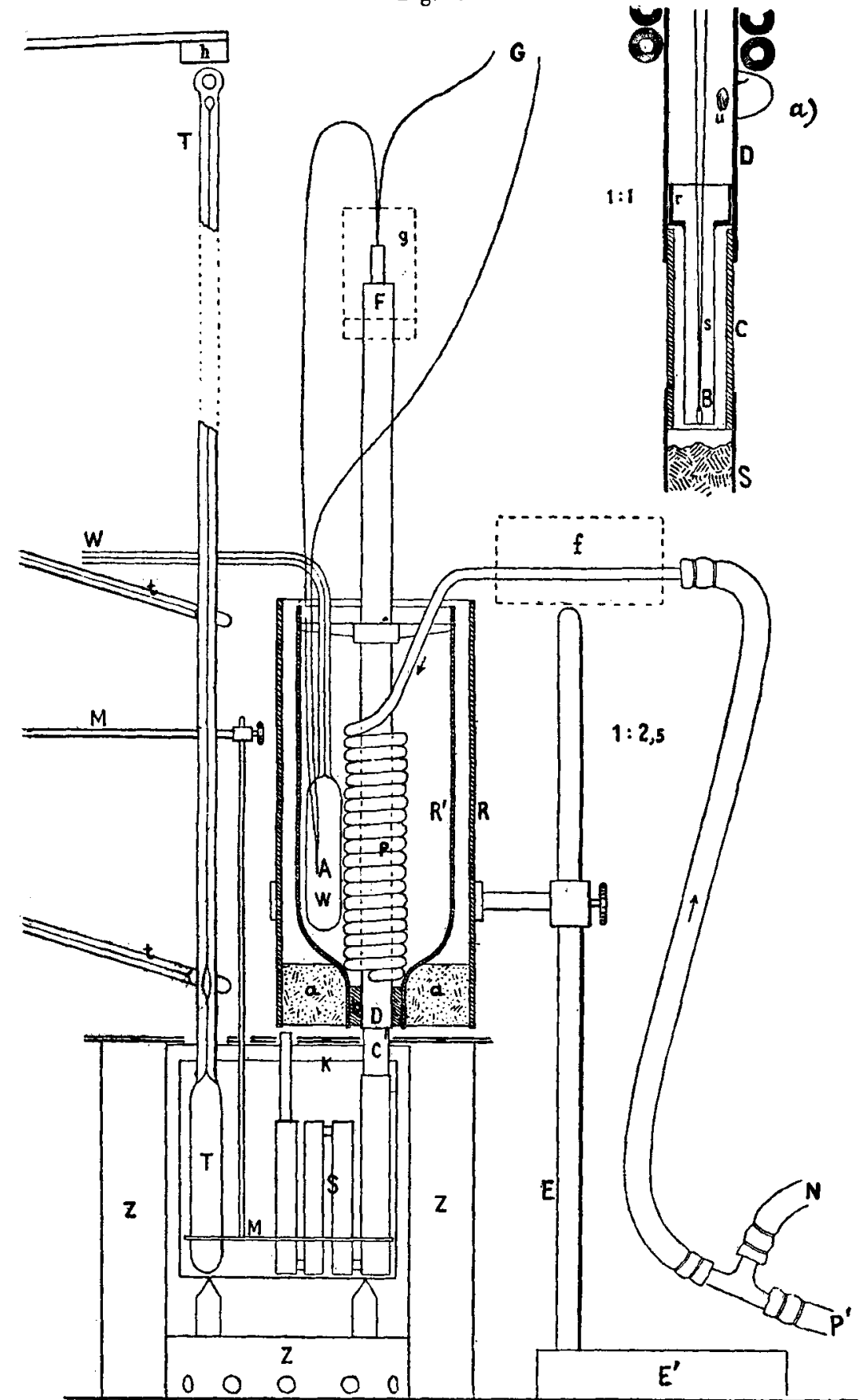
The calorimeter $\mathrm{K}-\mathrm{a}$ vessel of thin sheet silver, capacity about 250 cub. centims., weight 98.310 grammes-rests an three pointed glass feet inside a double-walled brass enclosure Z, protected on the outside by sheets of paper and cottonwool; the space between the walls is filled with water. Through several openings in the double sheet-brass cover of the enclosure there are introduced into the calorimeter:(1) the cooler $\mathrm{S},(2)$ the stirrer M, the oscillations of which are maintained by a heavy pendulum (not shown), (3) the thermometer $\mathrm{T}$.

The thermometer $\mathrm{T}$, an excellent instrument furnished by G. Fontaine of Paris, was divided in $0.02 \mathrm{degr}$. (from $-0^{\circ} .5$ to $+0^{\circ} \cdot 6$ and $+11^{\circ} .5$ to $+22^{\circ} 3$ ). It has been standardized with reference to the bydrogen scale by the Central Oflice of Weights and Measures at Vienna. 'The corrections proved so insignificant that it was possible to omit them altogether. Weight of glass and mercury was determined by the maker. $h$ represents a small electromagnetic hammer, destined to shake the thermometer $\mathrm{T}$, in order to prevent any lagging of mercury. $t$ and $t^{\prime}$ are two auxiliary thermometers by means of which the temperature of the stem of the principal thermometer was determined in order to obtain the well-known thermometric correction.

The heater was constructed as follows:-A copper tube $P$, one metre in length, internal diameter $=2$ millim., external diameter $=4$ millim., is coiled round a vertical brass tube D F, fixed along the axis of the heater. The outer end of the copper tube is joined by means of a thick-walled indiarubber tube with a $T$-shaped piece. One of its ends $\mathrm{P}^{\prime}$ is connected with the flasks filled with compressed air, the other $N$ with an open mercury manometer, which serves to control the velucity and steadiness of the current of air. The inner end of the copper spiral is connected by solder with the brass tube D F, near its lower end, where a small hole ( $u$, fig. $2 a$ ) is provided, through which the air cooled in the spiral passes into the brass tube, and thence through the connecting piece $\mathrm{C}$ into the cooler $\mathrm{S}$. The connexion consists of a thin-walled glass tube C, some 25 millims. in total length, its upper end being cemented by means of isinglass into the brass tube D F, the lower end into the cooler $S$ by sealing-wax. The glass tube serves only to provide an air-tight connexion and to protect against external heat the inner tube $s$, which is the real delivering tube of the gas. The last-mentioned tube $s$ is made of very thin highly-polished sheet silver; it is soldered to 
a silver collar $r$, fixed tightly in the brass tube DF, just above the end of the glass tube $\mathrm{C}$.

In the axis of $s$, some 3 or 4 millims. from its mouth, there is fixed one of the solderings $B$ of the thermo-electric couple, composed of very thin wires of copper and nickel. The wires pass freely throngh the brass tube $\mathrm{DF}$; near its upper end they are cemented by shellac into a capillary glass tube, the end of which can be seen in fig. 2, protruding over the end of DF. The capillary is fixed here by a cork, tightened by means of marine glue. In order to protect the cement against the cold the end $\mathrm{F}$ of the brass tube is dipped in water contained in a small glass heaker (indicated by dotted lines). One of the wires of the couple (copper) leads to the galvanometer $\mathrm{G}$, the other to the heater, where the second soldering $A$ is in contact with the bulb $W$ of the hydrogen thermometer.

This construction of the connecting piece was devised in agreement with the remarks of $\$ 5$. The silver tube $s$, being a good conductor of heat, assumes a temperature which differs very little from that of the heater; the gas is thus conducted into the cooler through a channel of nearly its own temperature. At the same time the polished silver tube is a bad radiator, and therefore it prevents effectually any interchange of heat between the heater and the cooler, with the exception of that due to the air current.

Secondly, the silver tube $s$ forms part of the thermometric arrangement, constructed upon the principle of aspiration. The air passes through the relatively narrow channel $s$ with a sufficiently great velocity, and it communicates its temperature very quickly to the soldering $B$ of the couple. In order to shield the soldering against the radiation of the cooler $\mathrm{S}$, the temperature of which is generally very different from that of the gas, it is advisable to place the soldering at some distance from the mouth of $s$, so as to reduce as far as possible the cone of rays passing from $B$ to $S$. This radiation is also intercepted by a small silver bridge, put across the mouth of the tube $s$, which serves at the same time to keep in place the soldering $\mathrm{B}$, which is tied to it by a bit of cocoon fibre.

The cooler $\mathrm{S}$ is made entirely of silver; it is quite similar to that employeci by $\mathrm{E}$. Wiedemann in his researches on the specific heat of gases. Four vertical silver tubes are connected by short pieces of silver tubing, alternately near their upper and lower ends. They are filled with compressed silver 
turnings (fine silver thread-tape) ; the whole weighs 30.024 grammes. I have found that this number of tubes is more than sufficient to allow perfect equalization of temperatures of the gas and the water.

The heater is placed vertically along the axis of a rather wide glass tube $R^{\prime}$, which acts as a receiver of the freezingmixtures. Near its lower end it is contracted into a narrow neck, in which the end $D$ of the axial brass tube is fitted tightly by means of an indiarubber ring. Another glass cylinder $R$ of larger diameter surrounds the vessel $R^{\prime}$; its bottom a consists of a varnished cork, in a perforation of which the neck of $R^{\prime}$ is fitted. The glass cylinder and the cork act as insulators against heat.

When liquid oxygen was to be applied as frigorific medium I found it economic to cool the current of air previously to its passing into the copper coil P. For that purpose a small metallic trough $f$ (indicated by dotted lines) was provided, which was filled with a mixture of solid carbon dioxide and ether.

In order to determine the specific heat of gases at higher temperatures, for instance at $+100^{\circ}$, the same form of apparatus could obvionsly be used with the glass receiver $\mathrm{R}^{\prime}$ replaced by some form of steam-heating. In my first experiments, however, I used a slightly different form (fig. 3). The connexion of the brass tube D F with the cooler, the thermometric arrangement, \&c., are exactly like those in the apparatus for low temperatures. Instead of the copper spiral the heating of the gas is accomplished, as in Wiedemann's apparatus, in a wide horizontal brass tube $P$, filled with copper turnings, and soldered at a right-angle to the tube $\mathrm{DF}$. Both tubes are placed permanently in a brass trough $\mathrm{R}$, being soldered to it. The temperature of $+100^{\circ}$ was obtained by boiling water in the trough, with the use of a small gasburner G. The soldering $A$ of the thermo-electric couple was heated in a separate steam thermostat. On this occasion I found (after having lost much time in search of an error in all parts of the apparatus) that the wires of the couple leading into the thermostat ought to be very fine, otherwise the soldering. would not acquire the temperature of $+100^{\circ}$, even in a copious current of steam.

$\S 8$. The initial temperature of the gas was determined, as already mentioned, by means of a thermo-electric couple (copper-nickel) in connexion with a hydrogen thermometer., It will be useful to say a few words on the mode of calculation of the temperature. 
The thermo-electric current was measured by means of a Despretz galvanometer, resistance about 145 ohms, the sensitiveness of which was very constant and relatively considerable -163,500,000 scale-divisions per ampere; this number has been tested frequently, also by means of a thermo-electric couple, at temperatures $0^{\circ}$ and $+100^{\circ}$.

The calibration of the couple was performed as follows:One of the solderings being placed in melting ice, the other

Fig. 3.

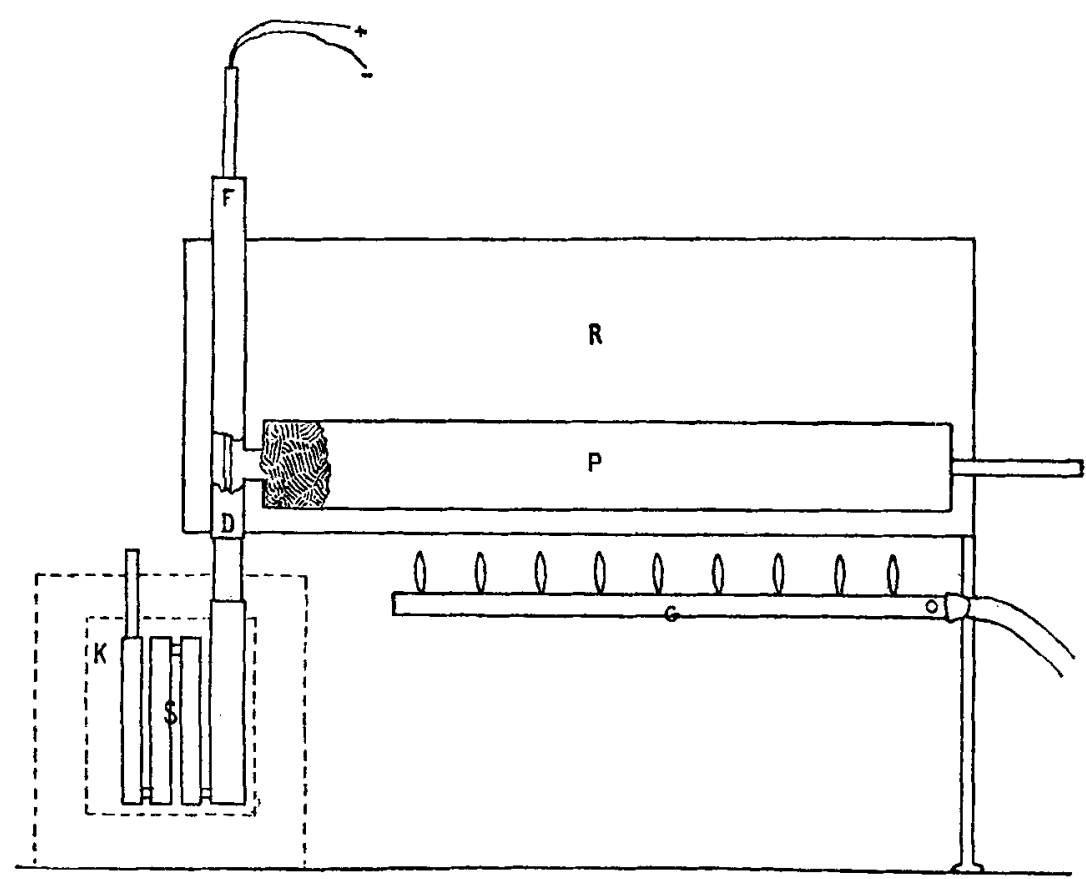

was heated or cooled, together with the bulb of the hydrogen thermometer, to different temperatures : $\vartheta=+100^{\circ},+19^{\circ} \cdot 6$, $-79^{\circ} \cdot 0,-104^{\circ} \cdot 0,-182^{\circ} \cdot 5$. Let us denote by $\mathrm{E}_{0}^{9}$ the electromotive forces observed (products of galvanometer deflexions and total resistance), and write

$$
\mathrm{E}_{0}^{\mathcal{P}}=\vartheta f(\vartheta) \text {. }
$$


The experiments furnished the following values of the function $f(\Im):-$

$$
\begin{array}{rrrrrr}
\vartheta & =+100^{\circ}, & +19^{\circ} \cdot 6, & -79^{\circ} \cdot 0, & -104^{\circ} \cdot 0, & -182^{\circ} \cdot 5 . \\
f(\vartheta) & =3788, & 3429, & 2945, & 2804, & 2345 .
\end{array}
$$

It will be remarked that the law of Tait and Avenarius is not strictly fulfilled, since these numbers do not obey the law of linear variation.

Suppose now one of the solderings to be heated to 9 degrees, the other to some higher temperature $\vartheta^{\prime}$. Then the electromotive force will be:-

$$
\mathrm{E}_{9}^{\vartheta^{\prime}}=\mathrm{E}_{0}^{9^{\prime}}-\mathrm{E}_{0}^{\vartheta}=\vartheta^{\prime} f\left(\vartheta^{\prime}\right)-\vartheta f(\vartheta) .
$$

If the difference between the temperatures $\vartheta$ and $\vartheta^{\prime}$ is a small one, as it was in my calorimetric experiments, where $\checkmark-\vartheta$ corresponded to the small loss of temperature of the gas in its passage from the heater to the calorimeter, then we may write

$$
f^{\prime}\left(\vartheta^{\prime}\right)=f(\vartheta)+\left(\vartheta^{\prime}-\vartheta\right) \frac{\partial f(\vartheta)}{\partial \vartheta}
$$

and therefore

\begin{tabular}{|c|c|c|}
\hline 9. & $\frac{\partial f(9)}{\partial^{9}}$ & $\mathrm{E}_{9}^{9+1}$. \\
\hline+100 & $4 \cdot 42$ & 4230 \\
\hline-79 & $5 \cdot 22$ & 2533 \\
\hline-104 & $5 \cdot 62$ & 2220 \\
\hline-182 & $6 \cdot 06$ & 1242 \\
\hline
\end{tabular}

$$
\mathrm{E}_{\Im}^{9^{\prime}}=\left(\vartheta^{\prime}-\vartheta\right)\left\{f(\vartheta)+\vartheta \frac{\partial f(\vartheta)}{\partial \vartheta}\right\} .
$$

Using the values of $f(\vartheta)$ given before it is easy to calculate graphically the values of the differential coefficient $\frac{\partial f(\vartheta)}{\partial \vartheta}$,
and to construct the following table:-

The numbers headed $\delta_{9}^{9+1}$ have been obtained by division of 
$\mathrm{E}_{9}^{9+1}$ by the total resistance of the circuit $(148 \cdot 3 \mathrm{ohms})$, they denote the galvanometer deflexions per degree of difference of temperature at a mean temperature $\vartheta$. These numbers I have used to reduce the galvanometer deflexions observed during the calorimetric work, in order to obtain the losses of temperature of the gas.

$\S 9$. Every one of the calorimetric determinations was conducted as follows :-After weighing the metal flasks filled with compressed air, and testing them for any possible leakage, they are connected with the calorimeter. Next the calorimetric vessel is charged with water from a small distilledwater bottle, as used in chemical liboratories, and the weight of the charge determined by observing the loss of weight of the bottle. Lastly, the heater is filled with the corresponding frigorific medium (carbon dioxide, ethylene, or oxygen), the stirrer started, and during a fow minutes (10) the following temperatures are read at noted times:-temperature of the calorimeter, of the two auxiliary thermometers $t$ and $t^{\prime}$, of the hydrogen thermometer. At the end of the tenth minute a first assistant starts the current of air, with some determinate speed, as registered by the mercury manometer, and tries to keep it as steady as possible by handling the screw valves of the flasks. At the same time a second assistant begins to observe the galvanometer deflexions, noting them at each half minute contemporaneously with the readings of the temperature of the calorimeter. During these observations the moment is noted when, the flasks being emptied, the current ceases and the mercury column in the manometer falls down to zero. At this time the auxiliary thermometers are read again, as well as the hydrogen thermometer. Daring the next ten minutes the rate of cooling or heating of the calorimeter is again observed. The experiment closes with the weighing of the empty Hasks.

The whole course of a determination and calculation of results will be best understood with the help of the following example :-

Air cooled by liquid ethylene. Weight of air (corrected) 48.8842 grammes. Weight of water $=244.410$ grs. Reduced weight of calorimeter $=253.829$ grammes water. Reading of manometer $=70$ centims. of mercury (corresponding to a current of about $15.3 \mathrm{grs}$. of air per minute). The following temperatures were observed :- 


\begin{tabular}{|c|c|c|c|c|}
\hline Minutes. & $\begin{array}{l}\text { Temp. of } \\
\text { calorimet. }\end{array}$ & $\begin{array}{l}\text { Hydrogen } \\
\text { thermon. }\end{array}$ & $\begin{array}{l}\text { Galvanom. } \\
\text { deflexion } \\
\text { millim. }\end{array}$ & $\begin{array}{c}\text { Auxiliary } \\
\text { thermometers. }\end{array}$ \\
\hline 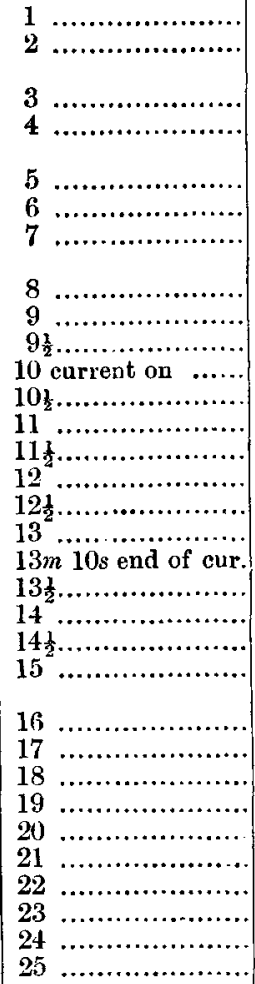 & $\begin{array}{r}20.954 \\
868 \\
781 \\
694 \\
601 \\
517 \\
420 \\
\\
329 \\
240 \\
196 \\
152 \\
19 \cdot 61 \\
18 \cdot 70 \\
17 \cdot 79 \\
16 \cdot 95 \\
16.08 \\
15 \cdot 25 \\
\\
14 \cdot 58 \\
14.523 \\
522 \\
520 \\
\\
510 \\
494 \\
476 \\
460 \\
410 \\
419 \\
400 \\
379 \\
360 \\
341\end{array}$ & $\begin{array}{l}-103.51 \\
-103.50 \\
-103.50\end{array}$ & $\begin{array}{r}250 \cdot 4 \\
29 \cdot 6 \\
29 \cdot 7 \\
30 \cdot 7 \\
30 \cdot 2 \\
30 \cdot 4 \\
30 \cdot 3 \\
\\
103 \cdot 0\end{array}$ & $\begin{array}{l}t=18 \cdot 2, t^{\prime}=16 \cdot 4 \\
t=18 \cdot 0, t^{\prime}=18 \cdot 4\end{array}$ \\
\hline
\end{tabular}

With the aid of the numbers recorded in the 1st and 2nd columns of the above table a curve is drawn, representing the variations of temperature of the calorimeter. It is composed of three nearly straight parts (the regular course of which serves as a proof that the readings are free from mistakes); the inclination of the first and third branches enables us to determine the influence of external heating or cooling on the temperature of the calorimeter. We find easily in the present example:- 


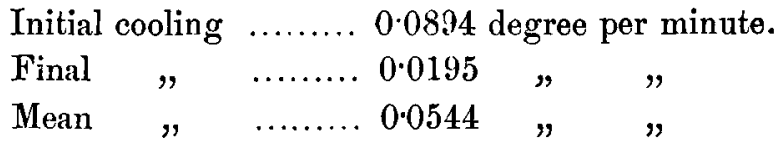

This mean value $I$ accept as determining the external cooling influence during the principal period of the experiment, when the gas current is flowing. I have found that this simple mode of reckoning gives nearly identical results with the more elaborate method of calculating the corresponding correction which has been proposed by Reynault. It seems, moreover, that a more laborious determination of the external heating or cooling effect would be useless, on account of the following anomily, which presented itself in a more or less marked degree in every experiment:-The transition from the rapid fall of temperature, caused by the cold gas-stream, to the less marked cooling observable during the final period, is always preceded by a slight depression of temperature (as in the preceding example); in experiments at high temperatures the phenomenon is exactly reversed. Undoubtedly these anomalous variations of temperature are caused by the fact that the direct conduction of heat (or cold) from the heater to the calorimeter is slightly modified by the gascurrent itself. This disturbing cause did not escape the attention of Regnault (l.c. pp. 83, 214), but he did not succeed either in getting rid of it, or in taking it into account. Some uncertainty thus remains in every determination of the specific heat.

In the foregoing example I considered the movement of heat as finished at the end of the 14 th minute. The initial and final temperatures of the calorimeter are thus :-20.152 and 14.523 ; when corrected with regard to the temperatures of the stem $\left(t\right.$ and $\left.t^{\prime}\right)$ they are :-20.162 and 14.514, whence the total fall of temperature $=5 \cdot 648$. From this there is to be subtracted the fall of temperature caused by external influences $(0.0544$ per minute), the amount of which is :$4 \times 0.0544=0.218$. Thus we obtain the corrected fall of temperature $=5^{\circ} \cdot 430$.

As regards the initial temperature of the air, it is equal to $-103 \cdot 50+2 \cdot 01=-101^{\circ} \cdot 49$, because the mean detlexion 30.15 millims. on the galvanometer-scale corresponds to a gain of 2.01 degrees. The final temperature of the gas is to be calculated by taking the arithmetic mean of the temperatures of the calorimeter at the beginning $(20 \cdot 16)$ and at the end of the current; the latter we find on the temperature- 
curve, it is $14^{\circ} .94$. Therefore final temp. $=17^{\circ} .55$, total rise of temperature of the gis $=101 \cdot 49+17 \cdot 55=119^{\circ} \cdot 04$.

Accurding to Bartoli and Stracciati the specific heat of water at the temperature of the experiment is 0.9996 , the sp. heat at $+15^{\circ}$ being taken as unity. Therefore we have finally :

$$
253.829 \times 0.9996 \times 5 \cdot 430=c_{1} \times 48.8342 \times 119 \cdot 04 \text {, }
$$

whence it follows : $c_{1}=0.2368$ as the mean value of the specific heat of air between the limits $-17^{\circ}$ and $+100^{\circ}$.

$\$ 10$. In the annexed table I have collected all the data serving to characterize the different determinations of the specific heat of air at constant atmospheric pressure. The columns headed I.-XI. contain the following quantities:-

I. Mass of air passed through the calorimeter in grs.

II. Equivalent mass of calorimeter in grs. of water.

III. Velocity of current : grs. per min.

IV. External heating of calorimeter, before and after the current, in $\frac{1}{10,000}$ degr. per min.

$\nabla$. Time of influx of heat into the calorimeter in minutes.

VI. Initial and final temperatures of calorimeter (corr.).

VII. Total rise of temperature (corrected).

VIII. Difference of temperatures of heater and gas, as indicated by the galvanometer (degrees).

IX. Initial and final temperature of the gas (degrees).

$\mathrm{X}$. Specific heat of air, under a pressure exceeding slightly the atmospheric, between temperatures indicated in IX.

XI. Mean values of the foregoing.

The whole of these results may be summed up as follows:-

$$
\begin{aligned}
& \text { Between }+20^{\circ} \text { and }+98^{\circ} \ldots \ldots \ldots \ldots c_{1}=0.2372 \\
& " \quad-77^{\circ}, \quad+16^{\circ} \ldots \ldots \ldots \ldots . . c_{1}=0.2374 \\
& "-102^{\circ} ",+17^{\circ} \ldots \ldots \ldots \ldots . . . c_{1}=0.2372 \\
& \text { " }-170^{\circ}, \quad+18^{\circ} \ldots \ldots \ldots \ldots . . . c_{1}=0.2427
\end{aligned}
$$

On the ground of these results we may assert with certainty that the specific heat $c_{1}$ does not vary in a sensible manner down to a temperature of about $-100^{\circ}$. At the lowest temperatures, however, there is apparently a small increase in the quantity $c_{1}$ of about 2 per cent. But $I$ think there is sufficient reason to conclude that even this small increase is only apparent, namely, that it ought to be ascribed to the influence of pressure rather than to that of the temperature.

Plil. Mag. S. 5. Vol. 42. No. 254. July 1896. 


\begin{tabular}{|c|c|c|}
\hline$\dot{\nabla}$ & $r$ & - \\
\hline$\dot{x}$ & 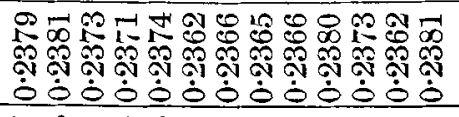 & 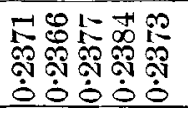 \\
\hline \multirow{2}{*}{$\ddot{A}$} & 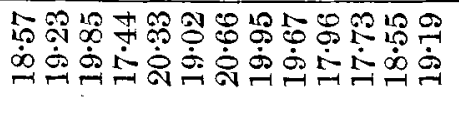 & 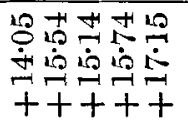 \\
\hline & 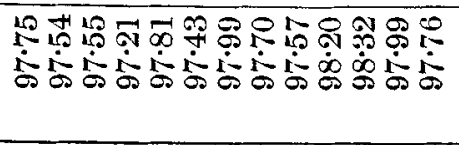 & 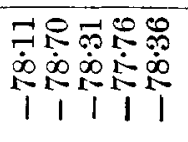 \\
\hline 止 & 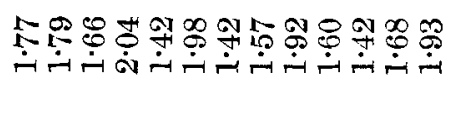 & 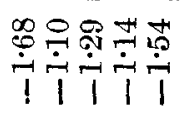 \\
\hline$\ddot{\beta}$ & 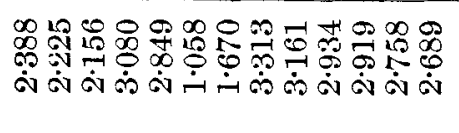 & 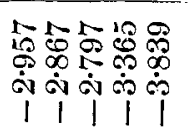 \\
\hline \multirow{2}{*}{$\dot{P}$} & 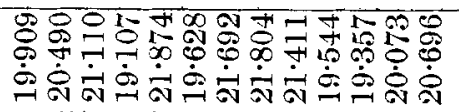 & 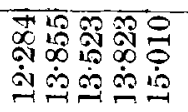 \\
\hline & 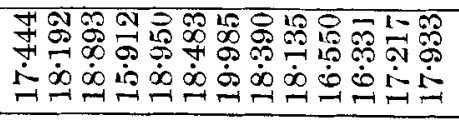 & 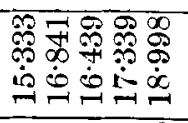 \\
\hline$\not>$ & 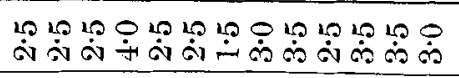 & 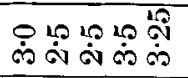 \\
\hline \multirow[b]{2}{*}{$\vec{A}$} & 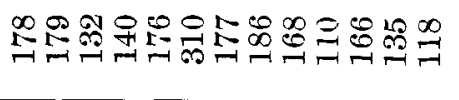 & 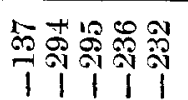 \\
\hline & 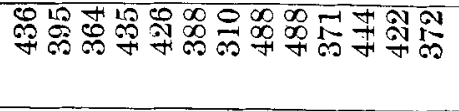 & $\begin{array}{lllll}1 & 1 & 1 & 1\end{array}$ \\
\hline$\exists$ & 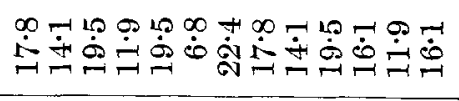 & $\ddot{\emptyset}$ \\
\hline$\stackrel{\mapsto}{\oplus}$ & 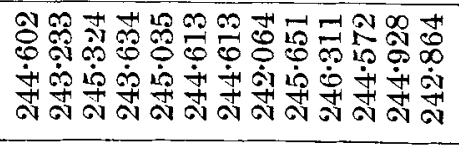 & 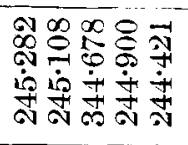 \\
\hline$\mapsto i$ & 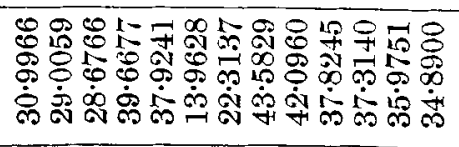 & 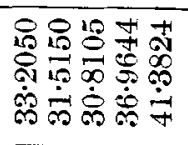 \\
\hline
\end{tabular}




\begin{tabular}{|c|c|c|}
\hline & + & 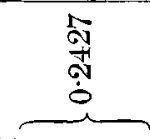 \\
\hline 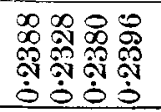 & 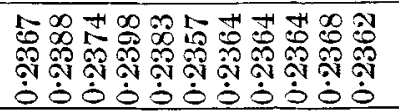 & 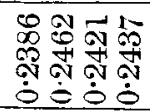 \\
\hline 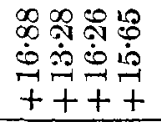 & 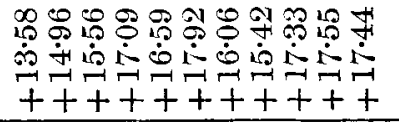 & $\begin{array}{l}-1000 \\
0100 \\
10+1+\infty \\
+1+++\end{array}$ \\
\hline 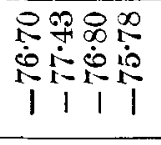 & 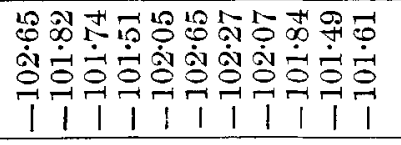 & 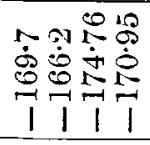 \\
\hline 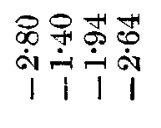 & 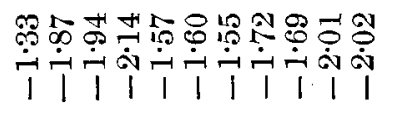 & 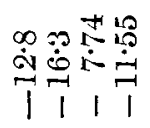 \\
\hline 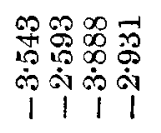 & 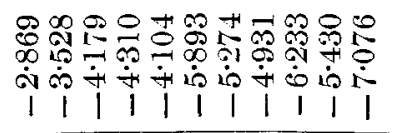 & 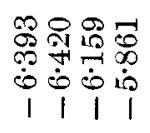 \\
\hline 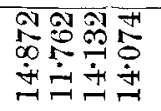 & 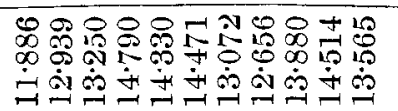 & 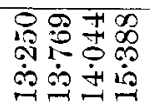 \\
\hline 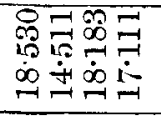 & 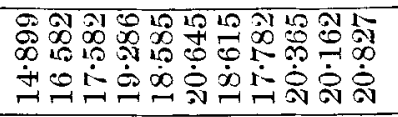 & 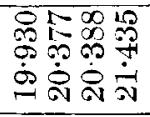 \\
\hline 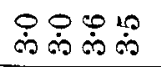 & 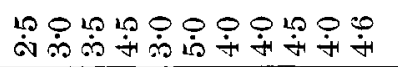 & 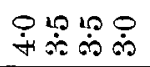 \\
\hline 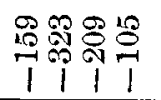 & 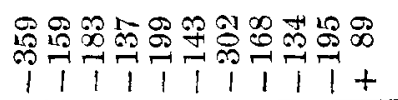 & 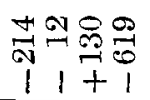 \\
\hline$\sum_{111}^{\infty} \underbrace{\infty}_{1} 88$ & 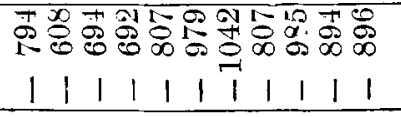 & 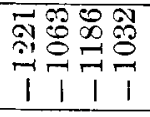 \\
\hline 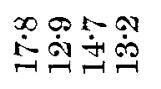 & 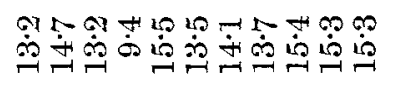 & 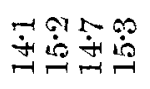 \\
\hline 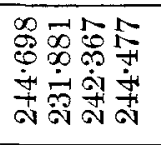 & 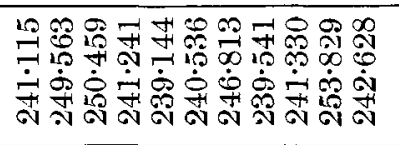 & 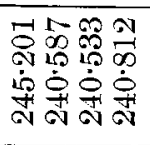 \\
\hline 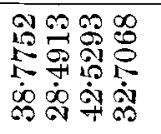 & 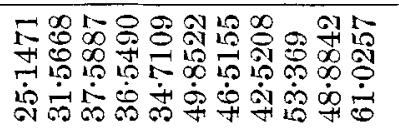 & 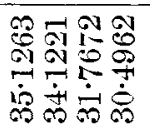 \\
\hline
\end{tabular}


Indeed, we shall see later on that the influence of pressure on the specific heat at very low temperatures is very considerable; for instance, at a temperature of $-144^{\circ}$ a doubling of the atmospheric pressure brings about an increase of specific leat by 0.03 . Now the air on entering the heater is clearly under a pressure exceeding the atmospheric by an amount indicated by the mercury manometer. In the liquid-oxygen series of my experiments this was about 70 centims. of mercury. Part of this pressure-head is absorbed by the resistance of the heater; but on entering the cooler there remained still an additional pressure of about 48 centims. This is amply sufficient to account for the observed small increase of the specific heat.

In what follows I shall therefore consider the specific heat of air under atmospheric pressure as a constant $(0.2372)$ from $+100^{\circ}$ down to $-170^{\circ}$.

$\S 11$. We are now prepared to take up the more general problem proposed in $\S 2$, to determine the dependence of the specific heat $c$ on pressure, at different temperatures. That a dependence of this kind does really exist may be inferred from the fact that the values of the second differential coefficient $\frac{\partial^{2} v}{\partial t^{2}}(\S 2$, equation 1$)$ are in general different from zero. The values of $\frac{\partial^{2} v}{\partial t^{2}}$ can be obtained from the results recorded in the first part of the present memoir. Denoting by $v$ the volume, under the pressure $p$, at $\theta$ degrees, of a mass of air which occupies the volume 1 at $0^{\circ}$, under atmospheric pressure, we have

$$
v=\frac{\eta_{0}}{p}(1+\alpha \theta) ; . . . \quad . \quad . .
$$

a denotes here the mean coefficient of expansion under the pressure $p$, between $0^{\circ}$ and $\theta^{\circ}, \eta_{0}$ the coefficient of compressibility at $0^{\circ}$, depending on $p$ only. The values of a have been given in a table in $\S 15$, those of $\eta_{0}$ will be found in the table of compressibility (\$17, vol. xli. p. 309) in the column headed " $0 . "$ "

In what follows I shall assume

$$
t=273+\theta \text {. }
$$

In order to obtain $\frac{\partial^{2} v}{\partial t^{2}}$ I chose the graphical method of calculation, which seemed more direct and reliable than the use of empirical formulas such as those of Clausius, van der 
Waals, \&c. It is most advantageous to perform the differentiations upon that quantity which has been directly measured, and the variations of which are most marked, i.e. upon the coefficient $\alpha$. Differentiating twice equation (6) we obtain

$$
\frac{\partial^{2} v}{\partial t^{2}}=\frac{\partial^{2} v}{\partial \theta^{2}}=\frac{2 \eta_{0}}{p} \frac{\partial \alpha}{\partial \theta}+\frac{\eta_{0}}{p} \theta \frac{\partial^{2} \alpha}{\partial \theta^{2}} . \quad . \quad .
$$

To obtain $\frac{\partial \alpha}{\partial \theta}$ and $\frac{\partial^{2} \alpha}{\partial \theta^{2}}$ I constructed on a large scale a diagram of values of $\alpha$ arranged in curves of equal pressure, abscissæ representing temperatures; it is in fact the diagram alluded to in $\$ 14$ (Part I.). These curves were divided in short pieces, approaching to straight lines; the differences of ordinates of their ends gave $\frac{\partial \alpha}{\partial \theta}$; the values so obtained were considered as corresponding to the middle point of each piece.

Another diagram was then constructed with $\frac{\partial \alpha}{\partial \theta}$ as ordinates. The curves were carefully smoothed, care being taken to keep the whole of them in sight in doing so. The process of differentiation repeated furnished the values of $\frac{\partial^{2} \alpha}{\partial \theta^{2}}{ }^{*}$.

Using these values $\frac{\partial^{2} v}{\partial t^{2}}$ can be now calculated by equation (7). It would be superfluous to reproduce here the vast number of values thus obtained; some of them will be given later on. An idea of the curious shape of the curves $\frac{\partial^{2} v}{\partial t^{2}}$ can be obtained by inspection of Pl. I., where the values of $\frac{\partial^{2} v}{\partial t^{2}}$ have been collected on isothermals, from $-100^{\circ}$ to $-144^{\circ}$.

* It might be objected that this method of calculation is not capable of yielding results of any high accuracy. Indeed, it cannot be denied that in drawing long curves along a comparatively small number of observed points, the success depends in a large measure on the firmness of eye and steadiness of the drawer's hind. Yet on the other hand it is to be remarked that the curves contrul one snother, gross errors are thus easily avoided.

Although graphical differentiation, if accurately done, is a very tedious process, it is unfortunately not possible to perform it by mechanical means, since, as far as I know, mechanical differentiators (working in a similar mauner to the numerous integrators) do not exist. If I am right they are even imposible on dynamical grounds. 
The shape of these curves leads forcibly to the conclusion that for small pressures $\left(p=1\right.$ atm.) $\frac{\partial^{2} v}{\partial t^{2}}$ cannot be zero throughout the whole range of temperatures. It is very small indeed for temperatures above $-100^{\circ}$; but near the critical temperature its values camnot be neglected. This is, of course, an inference obtained by extrapolation (dotted parts of the curves on Pl. I.), since no experiments are available on expansion of air at low temperatures under atmospheric pressure.

Although this extrapolation does not seem to be doubtful, and, moreover, any errors in it do not influence the final result, namely the integral $\int_{1}^{p} \frac{\partial^{2} v}{\partial t^{2}} d p$, in a marked degree, yet it seemed desirable to test its probability in an indirect way. For that purpose I integrated twice the extrapolated values of $\frac{\partial^{2} v}{\partial \iota^{2}}$ (for $p=1 \mathrm{~atm}$.), with respect to temperature, by mechanical quadratures, adding to the result $1+\frac{\theta}{273}$ in lieu of constant of integration. It appears from this calculation that at a temperature $\theta=-140^{\circ}$ (hydrogen scale), a constant pressure (1 atm.) air-thermometer would indicate $-140^{\circ} \cdot 76$. I know of no experiments to corroborate this result. From Olszewski's experiments on constant volume gas-thermometers*) there may be quoted the following results: at a temperature of $-143^{\circ} \cdot 7$ (hydrogen scale) a constant volume nitrogen thermometer indicated $-144^{\circ} \cdot 4$, a similar oxygen thermometer $-145^{\circ} \cdot 5$. This is not inconsistent with the above extrapolation.

$\$ 12$. In order to obtain the values of the specific heat $c_{p}$, according to equation (4) it remains to calculate the integrals $\int_{1}^{p} \frac{\partial^{2} v}{\partial t^{2}} d p$, along the isothermals $\frac{\partial^{2} v}{\partial t^{2}}, p$ and $d p$ being expressed in atmospheres. These integrals multiplied by the respective absolute temperatures $t$ and by the constant factor 18.714 represent the difference between the specific heat $c_{p}$ and the specific heat $c_{1}$, under atmospheric pressure, which is very nearly a constant, $=0 \cdot 2372$.

The integrations have been performed by Simpson's formula, with the help of a large diagram of $\frac{\partial^{2} v}{\partial t^{2}}$, a reduced reproduction of which will be found on Pl. I. The results are embodied in the following tables:-

* "Rozprawy" of Cracow Acad. vol. xiv. (Math. Class). 


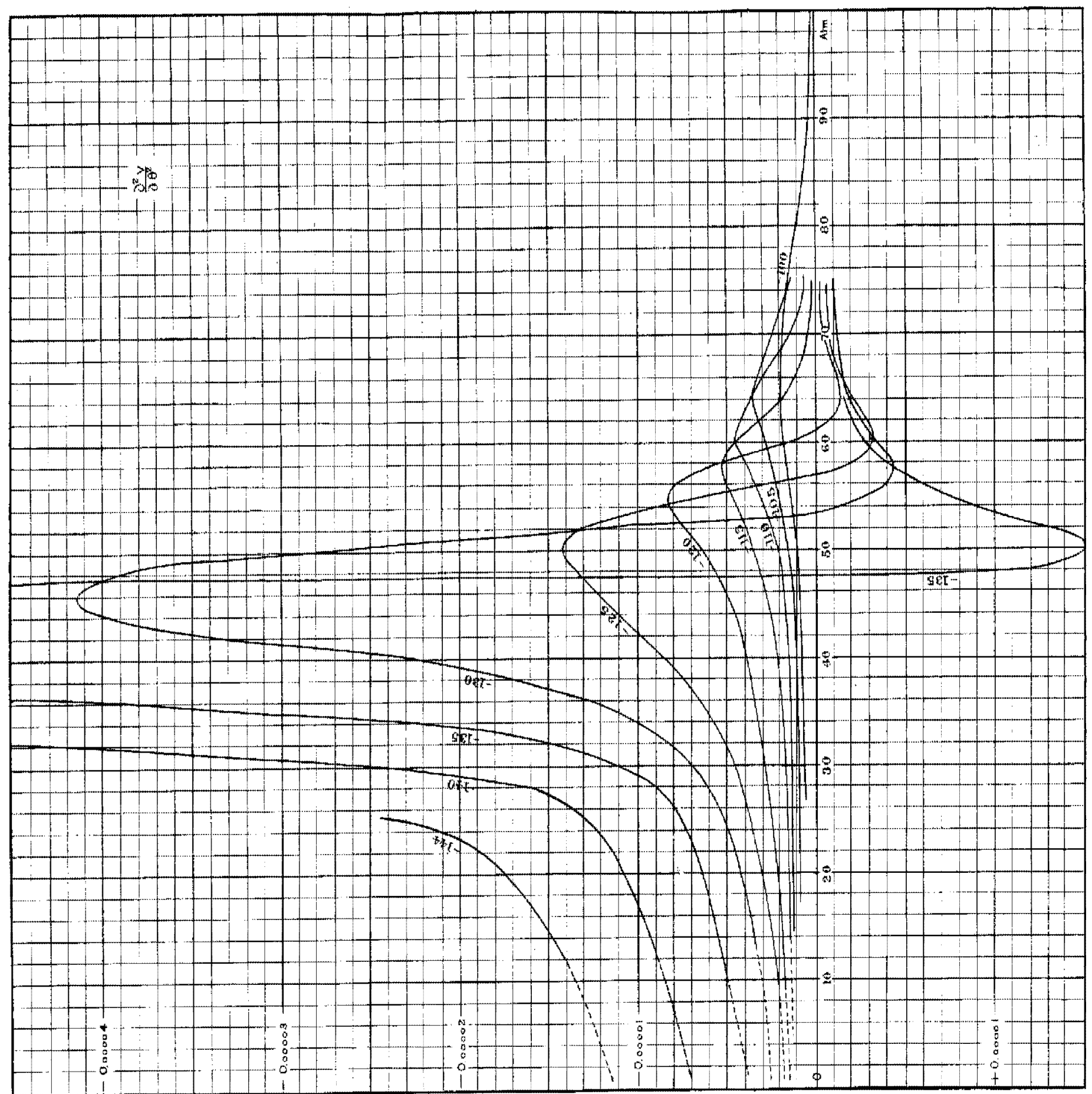


Thermodynamic Properties of Air.

$\theta=-144, t=129$.

\begin{tabular}{|c|c|c|}
\hline$p$. & $-10^{8} \frac{\partial^{2} v}{\partial t^{2}}$ & $c_{p}$ \\
\hline 10 & 1360 & 0.504 \\
20 & 1740 & $0 \cdot 866$ \\
25 & 2390 & $1 \cdot 101$ \\
\hline
\end{tabular}

$\theta=-140, \quad t=133$.

\begin{tabular}{|c|r|c|}
\hline$p$. & $-10^{8} \frac{\partial^{2} v}{\partial t^{2}}$ & $c_{p .}$ \\
\hline 10 & 850 & $0 \cdot 408$ \\
20 & 1670 & 0.640 \\
30 & 2395 & 0.993 \\
40 & 9064 & 2.607 \\
\hline
\end{tabular}

$\theta=-135, \quad t=138$.

\begin{tabular}{|l|r|l|}
\hline$p$. & $-10^{8} \frac{\partial^{2} v}{\partial t^{2}}$ & $c_{p}$ \\
& $-\frac{\partial^{\prime}}{}$ & \\
\hline 10 & 500 & $0 \cdot 339$ \\
20 & 648 & $0 \cdot 484$ \\
30 & 1110 & $0 \cdot 689$ \\
40 & 7115 & $15 \cdot 7$ \\
45 & 8699 & $2 \cdot 602$ \\
$47 \cdot 7$ & 0 & $3 \cdot 069$ \\
50 & -1501 & $3 \cdot 004$ \\
55 & -770 & $2 \cdot 848$ \\
60 & -295 & $2 \cdot 785$ \\
65 & -163 & $2 \cdot 758$ \\
\hline
\end{tabular}

$\theta=-130, \quad t=143$.

\begin{tabular}{|c|r|c|}
\hline$p$. & $-10^{8} \frac{\partial^{2} v}{\partial t^{2}}$ & $c_{p .}$ \\
\hline 10 & 311 & $0 \cdot 302$ \\
20 & 418 & 0.397 \\
30 & 685 & 0.536 \\
40 & 2293 & 0.873 \\
50 & 2880 & $1 \cdot 826$ \\
$53 \cdot 7$ & 0 & $1 \cdot 963$ \\
55 & -303 & $1 \cdot 957$ \\
60 & -357 & 1.905 \\
65 & -168 & 1.872 \\
70 & -108 & 1855 \\
75 & -100 & $1 \cdot 84: 2$ \\
\hline
\end{tabular}

$\theta=-125, \quad t=148$.

\begin{tabular}{|c|r|c|}
\hline$p$. & $-10^{8} \frac{\partial^{2} v}{\partial t^{2 .}}$ & $c_{p}$ \\
\hline 10 & 211 & $0 \cdot 283$ \\
20 & 300 & $0 \cdot 352$ \\
30 & 456 & $0 \cdot 452$ \\
40 & 825 & $0 \cdot 620$ \\
50 & 1406 & $0 \cdot 931$ \\
$56 \cdot 9$ & 0 & $1 \cdot 106$ \\
60 & -316 & $1 \cdot 087$ \\
70 & -76 & $1 \cdot 040$ \\
75 & -57 & $1 \cdot 031$ \\
\hline
\end{tabular}

$$
\theta=-120, t=153 \text {. }
$$

\begin{tabular}{|c|r|r|}
\hline$p$. & $-10^{8} \frac{\partial^{2} v}{\partial t^{2}}$ & ${ }^{c_{p} .}$ \\
\hline 10 & 151 & $0 \cdot 272$ \\
20 & 207 & $0 \cdot 322$ \\
30 & 271 & $0 \cdot 389$ \\
40 & 382 & $0 \cdot 479$ \\
50 & 610 & $0 \cdot 614$ \\
60 & 170 & $0 \cdot 802$ \\
$61 \cdot 1$ & 0 & $0 \cdot 805$ \\
70 & -56 & 0777 \\
75 & -17 & $0 \cdot 772$ \\
\hline
\end{tabular}

\begin{tabular}{|c|c|c|}
\multicolumn{3}{c}{$\theta=-115, t=158$} \\
\hline$p$. & $-10^{8} \frac{\partial^{2} v}{\partial t^{2}}$ & $c_{p}$ \\
\hline 10 & 121 & $0 \cdot 267$ \\
\hline 20 & 135 & 0.305 \\
30 & 159 & $0 \cdot 348$ \\
40 & 207 & 0.400 \\
50 & 335 & 0.476 \\
60 & 451 & $0 \cdot 604$ \\
70 & 41 & $0 \cdot 657$ \\
75 & 29 & $0 \cdot 662$ \\
\hline
\end{tabular}


$\theta=-110, t=163$.

\begin{tabular}{|c|c|c|}
\hline$p$. & $-10^{8} \frac{\partial^{2} v}{\partial t^{2}}$ & $c_{p}$ \\
\hline 10 & 108 & $0 \cdot 264$ \\
20 & 115 & $0 \cdot 298$ \\
30 & 119 & $0 \cdot 333$ \\
40 & 136 & $0 \cdot 370$ \\
50 & 204 & $0 \cdot 419$ \\
60 & 444 & $0 \cdot 509$ \\
70 & 152 & 0.607 \\
75 & 75 & $0 \cdot 623$ \\
\hline
\end{tabular}

$\theta=-105, t=168$.

\begin{tabular}{|c|c|c|}
\hline$p$. & $-10^{8} \frac{\partial^{2} v}{\partial t^{2}}$ & $c^{*}$ \\
\hline 10 & 89 & $0 \cdot 261$ \\
20 & 90 & $0 \cdot 288$ \\
30 & 93 & 0.317 \\
40 & 100 & 0346 \\
50 & 145 & $0 \cdot 382$ \\
60 & 279 & 0.445 \\
70 & 223 & 0.539 \\
75 & 115 & 0.564 \\
\hline
\end{tabular}

$$
\theta=-100, t=173 .
$$

\begin{tabular}{|c|c|c|}
\hline$p$. & $-10^{8} \frac{\partial^{2} v}{\partial t^{2}}$ & $c_{p^{*}}$ \\
\hline 10 & 77 & 0.258 \\
20 & 79 & $0 \cdot 283$ \\
30 & 80 & $0 \cdot 3119$ \\
40 & 81 & $0 \cdot 334$ \\
50 & 107 & 0.363 \\
60 & 180 & $0 \cdot 408$ \\
70 & 174 & 0.469 \\
80 & 97 & 0.512 \\
90 & 32 & 0.532 \\
100 & 13 & 0.538 \\
\hline
\end{tabular}

$\theta=-95, t=178$.

\begin{tabular}{|c|c|c|}
\hline$p$. & $-10^{8} \frac{\partial^{2} v}{\partial t^{2}}$ & $c_{p^{\prime}}$ \\
\hline 10 & 65 & $0 \cdot 250$ \\
20 & 67 & $0 \cdot 278$ \\
30 & 72 & $0 \cdot 301$ \\
40 & 79 & $0 \cdot 325$ \\
50 & 97 & $0 \cdot 354$ \\
60 & 122 & $0 \cdot 390$ \\
70 & 132 & $0 \cdot 432$ \\
80 & 107 & $0 \cdot 473$ \\
90 & 50 & $0 \cdot 499$ \\
100 & 26 & $0 \cdot 510$ \\
\hline
\end{tabular}

$$
\theta=-50, \quad t=223 \text {. }
$$

\begin{tabular}{|c|c|c|}
\hline$p$. & $-10^{8} \frac{\partial^{2} v}{\partial t^{\nu^{*}}}$ & ${ }^{c} p^{*}$ \\
\hline 10 & 19 & $0 \cdot 244$ \\
20 & 22 & $0 \cdot 252$ \\
30 & 26 & 0.262 \\
40 & 30 & $0 \cdot 274$ \\
50 & 32 & $0 \cdot 286$ \\
60 & 32 & 0.300 \\
70 & 30 & 0312 \\
80 & 29 & $0 \cdot 324$ \\
90 & 28 & 0.336 \\
100 & 27 & 0.347 \\
\hline
\end{tabular}

$$
\theta=0, t=273 .
$$

\begin{tabular}{|c|c|c|}
\hline$p$. & $-10^{8} \frac{\partial^{2} v}{\partial t^{2}}$ & $c_{p .}$ \\
\hline 10 & 9 & $0 \cdot 241$ \\
20 & 9 & $0 \cdot 245$ \\
30 & 9 & 0250 \\
40 & 9 & $0 \cdot 254$ \\
50 & 9 & $0 \cdot 259$ \\
60 & 9 & 0264 \\
70 & 9 & $0 \cdot 268$ \\
80 & 9 & $0 \cdot 273$ \\
90 & 9 & $0 \cdot 277$ \\
160 & 9 & $0 \cdot 282$ \\
\hline
\end{tabular}


The variations of the specific heat $c_{p}$, as revealed by these tables, have been represented in a graphical form on Pl. II. It will be remarked that with increasing pressure the specific heat increases, the more considerably the lower the temperature of the corresponding isothermal. In the vicinity of the critical temperature these increments are largest, and in the critical state itself the specific heat tends to infinity. This might have been anticipated, on the ground of equation (2), $\$ 2$, because $\frac{\partial p}{\partial v}=0$ in the eritical state, whilst $c_{v}$ and $\frac{\partial p}{\partial t}$ remain
finite.

The most interesting feature of the diagram (Plate II.) is that at temperatures above the critical the specific heat rises with increasing pressure only to a maximum value, corresponding to a certain limiting pressure (which is a function of the temperature). Under pressures exceeding this limiting value the specific heat remains nearly constant, with but a slight tendency to decrease. The lower the temperature, the smaller is this limiting pressure, and the more marked the transition from increase to approximate constancy of the specific heat. It would seem as if these pressures marked a limit between truly gaseous states and a gaso-fluid condition of matter, in which the intrinsic pressures attain a preponderance against which the external pressure has but little influence. It is interesting to note that the curves of the coefficient of expansion $\alpha$, under constant pressure (Part I., plate i.), show similar bends for pressures which are not much different from the limiting pressures of the specific-heat curres. We shall see that neither the curves of the specific heat at constant volume, nor those of the coefficient of expansion at constant volume, show any trace of bends of this sort.

$\S 13$. It is a more difficult matter to calculate the variations of the specific heat at constant volume. At first sight it would seem easiest to apply the equation (3), § 2 :-

$$
\frac{\partial c_{\mathrm{v}}}{\partial v}=\frac{t}{J_{\ln }} \frac{\partial^{2} p}{\partial \iota^{2}}
$$

But we shall see that the variations of pressure at constant volume are so nearly proportional to those of the temperature, that the calculation of the second differential coefficient $\frac{\partial^{2} p}{\partial t^{2}}$ is practically impossible.

In order to find the variations of pressure of air of any density kept at a constant volume, I shall refer once more to 


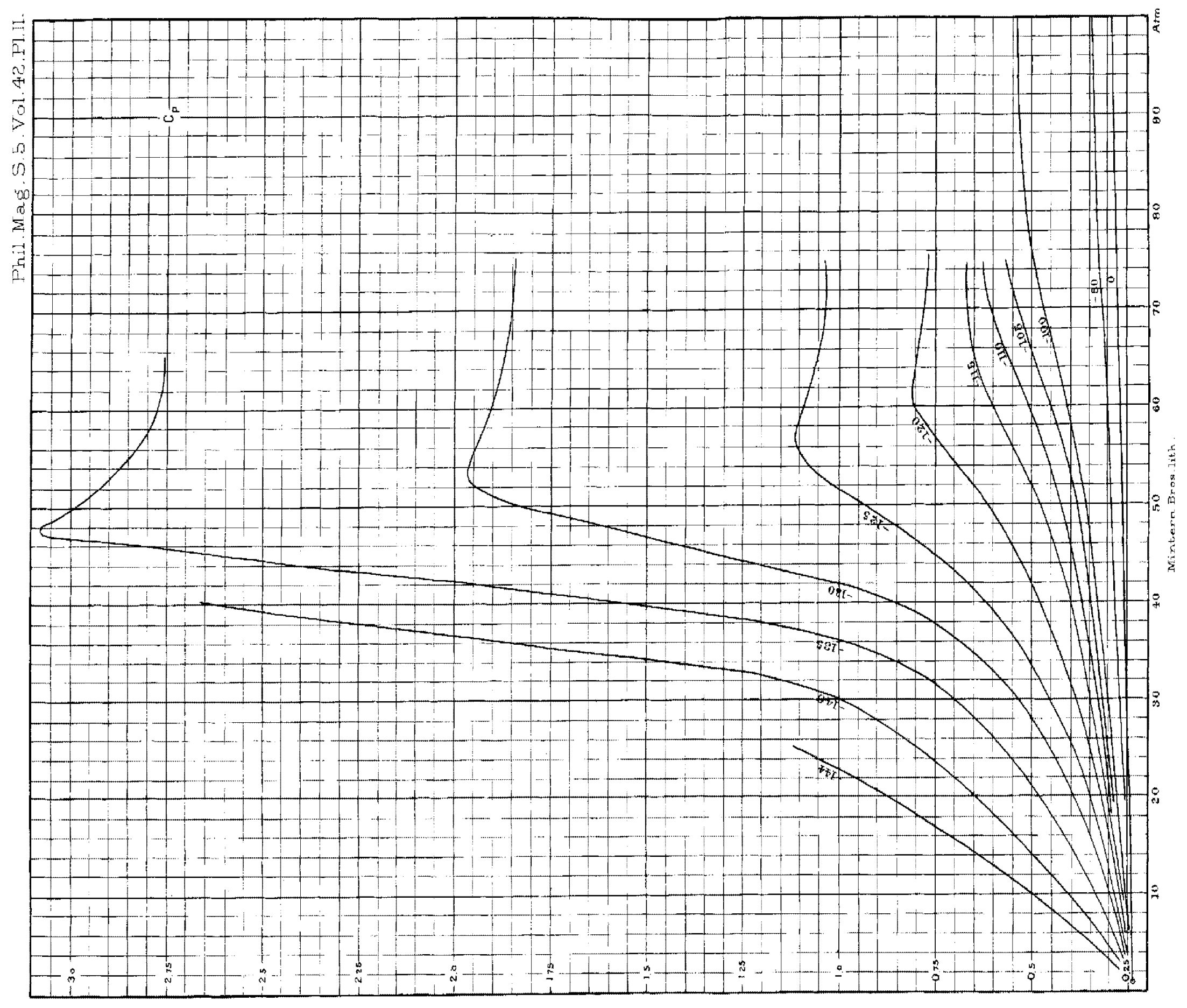


the results obtained in Part $I$. Through the origin of the diagram of compressibility (Part I., plate ii.) draw any straight line. The intersections of it with the isothermals $p v=$ const. mark evidently a series of pressures corresponding to the respective temperatures, and satisfying the condition $v=$ const. ; it is supposed that $v=1$ when $\theta=0^{\circ}$, and the pressure is atmospheric. Using the original diagram of $p v$, $I$ determined in this manner the constant volume relation of $p$ and $\theta$ for several densities of air, from $v=\frac{1}{10}$ to $v=\frac{1}{200}$. The results are given in the following table.

\begin{tabular}{|c|c|c|c|c|c|c|}
\hline$v=$ & $\frac{1}{10}$. & $\frac{1}{20}$. & $\frac{1}{25}$. & $\frac{1}{30}$ & $\frac{1}{40}$. & $\frac{1}{50}$. \\
\hline$\theta$. & \multicolumn{6}{|c|}{ Pressure in atmospheres. } \\
\hline $\begin{array}{l}+100 \\
+16 \\
0 \\
-35 \\
=78 \cdot 5 \\
-103 \cdot 5 \\
-130 \\
-135 \\
-140 \\
-145\end{array}$ & $\begin{array}{r}13 \cdot 680 \\
10 \cdot 542 \\
9 \cdot 949 \\
8 \cdot 640 \\
7 \cdot 005 \\
6.0665 \\
5 \cdot 055 \\
4 \cdot 850 \\
4.668 \\
4 \cdot 466\end{array}$ & $\begin{array}{r}27 \cdot 41 \\
21 \cdot 01 \\
19 \cdot 80 \\
17 \cdot 12 \\
13 \cdot 76 \\
11 \cdot 82 \\
9 \cdot 71 \\
9 \cdot 26 \\
8.87 \\
8 \cdot 43\end{array}$ & $\begin{array}{l}34 \cdot 28 \\
26 \cdot 20 \\
24 \cdot 68 \\
21 \cdot 30 \\
17 \cdot 05 \\
14 \cdot 60 \\
11 \cdot 90 \\
11 \cdot 32 \\
10 \cdot 8 \cdot 2 \\
10 \cdot 25\end{array}$ & $\begin{array}{l}41 \cdot 17 \\
31 \cdot 38 \\
29 \cdot 54 \\
25 \cdot 44 \\
20 \cdot 30 \\
17 \cdot 28 \\
14 \cdot 00 \\
13 \cdot 29 \\
12 \cdot 65 \\
11.95\end{array}$ & $\begin{array}{l}55 \cdot 08 \\
41 \cdot 70 \\
39 \cdot 20 \\
33 \cdot 67 \\
26 \cdot 64 \\
22 \cdot 48 \\
17 \cdot 99 \\
16 \cdot 98 \\
16 \cdot 14 \\
15 \cdot 10\end{array}$ & $\begin{array}{l}69 \cdot 09 \\
52 \cdot 10 \\
4874 \\
41 \cdot 70 \\
32 \cdot 75 \\
27 \cdot 40 \\
21 \cdot 65 \\
20 \cdot 35 \\
19 \cdot 2 ! \\
17 \cdot 97\end{array}$ \\
\hline$v=$ & $\frac{1}{60}$ & $\frac{1}{80}$ & $\frac{1}{100}$ & $\frac{1}{120}$ & $\frac{1}{150}$ & $\frac{1}{200}$ \\
\hline$\theta$. & \multicolumn{6}{|c|}{ Pressure in atmospheres. } \\
\hline $\begin{array}{l}+100 \\
+16 \\
0 \\
-35 \\
-78 \cdot 5 \\
-103 \cdot 5 \\
-130 \\
-135 \\
-140 \\
-145\end{array}$ & $\begin{array}{l}83 \cdot 28 \\
62 \cdot 34 \\
58 \cdot 33 \\
49 \cdot 70 \\
38 \cdot 65 \\
32 \cdot 10 \\
25 \cdot 08 \\
23 \cdot 40 \\
22 \cdot 08 \\
20 \cdot 40\end{array}$ & $\begin{array}{r}112 \cdot 14 \\
83 \cdot 04 \\
77 \cdot 52 \\
6550 \\
50 \cdot 06 \\
40 \cdot 88 \\
31 \cdot 08 \\
28 \cdot 74 \\
26 \cdot 74 \\
24 \cdot 50\end{array}$ & $\begin{array}{r}103 \cdot 92 \\
96 \cdot 80 \\
81 \cdot 00 \\
60 \cdot 80 \\
48 \cdot 75 \\
35 \cdot 90 \\
32 \cdot 90 \\
30 \cdot 35 \\
2735\end{array}$ & $\begin{array}{r}125 \cdot 41 \\
116 \cdot 40 \\
96 \cdot 40 \\
71 \cdot 02 \\
56 \cdot 49 \\
39 \cdot 95 \\
36 \cdot 18 \\
32 \cdot 84 \\
29 \cdot 12\end{array}$ & $\begin{array}{r}120 \cdot 00 \\
85 \cdot 83 \\
66 \cdot 13 \\
44 \cdot 80 \\
39 \cdot 60 \\
35 \cdot 39 \\
30 \cdot 30\end{array}$ & $\begin{array}{r}110 \cdot 80 \\
81 \cdot 50 \\
50 \cdot 32 \\
43 \cdot 44 \\
37 \cdot 80\end{array}$ \\
\hline
\end{tabular}


In fig. 4 we find a graphical representation of these results by means of curves of equal density.

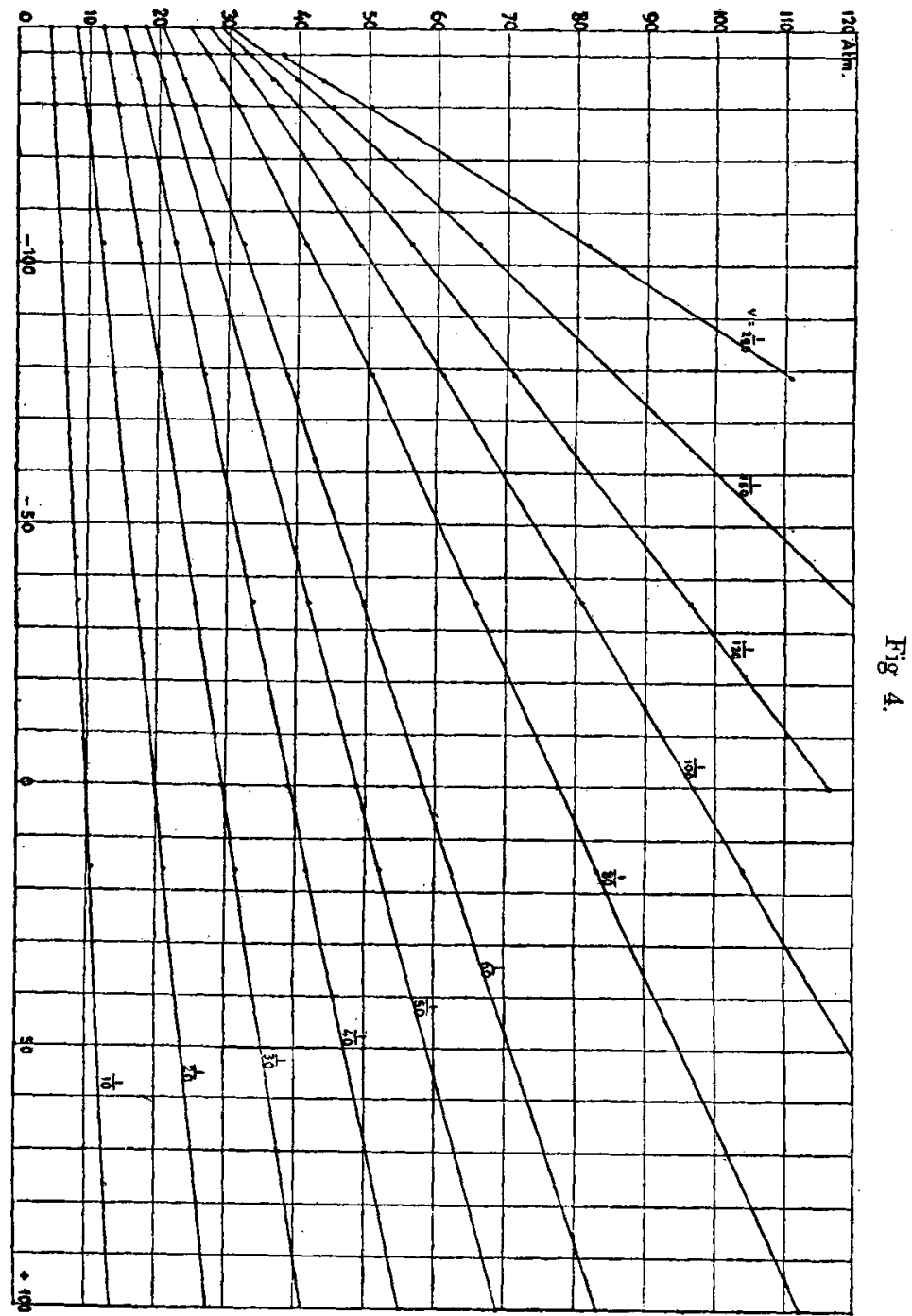

Some time ago Ramsay and Young announced an important generalization of the law of Charles, according to which the constant-volume relation of pressure and temperature (in the 
gaseous and liquid condition of matter alike) would be a linear one, at any density. It is now known that a law of that kind is not generally true, or that it holds good only approximately. Yet it is remarkable how nearly it is fulfilled in the case of atmospheric air at widely different temperatures and densities. The curves of fig. 4 depart only insignificantly from straight lines. But none of them cuts the axis of abscissæ at the point $-273^{\circ}$ - so often spoken of (by a curious confusion of ideas) as absolute zero -except, perhaps, those corresponding to very low densities; the pressure of dense gas decreases far more rapidly than that.

The constant-volume relation $p=\mathrm{F}(\theta)$ will be perhaps more clearly expressed by introducing the pressure-coefficient $\beta$ of expansion defined by the equation

$$
p=p_{0}(1+\beta \theta),
$$

$p_{0}$ being the pressure exerted at $0^{\circ}$ by the gas, when compressed to a density $\rho=\frac{1}{v}$ (unit of $\rho=$ density at $0^{\circ}$ under atmospheric pressure). The values of $\beta$ are as follows :-

\begin{tabular}{|c|c|c|c|c|c|c|}
\hline$\rho=$ & 20. & 40. & 60. & 80. & 100. & 120. \\
\hline 0. & \multicolumn{7}{|c|}{$100,000 \times \beta}$. \\
\hline+100 & 386 & 406 & 426 & 447 & & \\
$-78 \cdot 5$ & 387 & 409 & 431 & 452 & 474 & 496 \\
$-103 \cdot 5$ & 389 & 412 & 435 & 457 & 480 & 501 \\
-130 & 392 & 416 & 439 & 462 & 484 & 505 \\
-140 & 394 & 420 & 444 & 467 & 490 & 513 \\
-145 & 396 & 424 & 449 & 472 & 495 & 517 \\
\hline
\end{tabular}

The pressure coefficient does not vary much through a range of $245^{\circ}$, provided the density be kept constant. An increase of density causes it to augment rapidly. In contrast with the tortuous curves representing the coefficient $\alpha$, those of $\beta$ form a narrow nearly straight bundle, converging approximately to one point, namely, $\beta=0.00367$ for $\rho=1$.

\$14. From what has been just said, it follows that equation (3) is not suitable for calculating $c_{v}$. I preferred to 
use for that purpose the relation

$$
c_{v}=c_{p}+18 \cdot 714 \frac{\left(\frac{\partial p}{\partial t}\right)^{2}}{\frac{\partial p}{\partial v}},
$$

$i$. e. to obtain the values of the specific heat at constant volume by means of those of $c_{p}$ already calculated. To simplify the calculation, put $p v=\eta$; then it follows that

therefore

$$
\frac{\partial p}{\partial v}=\frac{p}{\frac{\partial \eta}{\partial p}-v}
$$

$$
c_{p}-c_{\mathrm{v}}=18 \cdot 714 \frac{t\left(\frac{\partial p}{\partial \theta}\right)^{2}\left(v-\frac{\partial \eta}{\partial p}\right)}{p} .
$$

The values of $\frac{\partial p}{\partial \theta}$ will be found easily by the preceding section; those of $\frac{\partial \eta}{\partial \mu}$ can be obtained by graphical differentiation on the diagram of compressibility (Part I., pl. ii.). The necessary data and the results of this calculation are collected in the following tables:-

$$
\theta=-140, \quad t=133 .
$$

\begin{tabular}{|l|c|c|c|c|c|c|}
\hline$v$. & $p$. & $c_{p .}$ & $\frac{\partial p}{\partial \theta}$ & $\frac{\partial \eta}{\partial p}$ & $c_{v .}$ & $\frac{c_{p}}{c_{D}}$ \\
\hline$\frac{1}{10} \ldots \ldots$ & 4.668 & 0.305 & 0.0392 & -0.0055 & 0.219 & 1.39 \\
$\frac{1}{20} \ldots \ldots$. & 8.87 & 0.385 & 0.083 & -0.0055 & 0.278 & 1.38 \\
$\frac{1}{30} \ldots \ldots$ & 12.65 & 0.464 & 0.1363 & -0.0055 & 0.322 & 1.44 \\
$\frac{1}{50} \ldots \ldots$. & 19.29 & 0.624 & 0.239 & -0.0059 & 0.433 & 1.44 \\
$\frac{1}{60} \ldots \ldots$ & 22.08 & 0.703 & 0.306 & -0.0066 & 0.457 & 1.54 \\
$\frac{1}{80} \ldots \ldots .$. & 26.74 & 0.859 & 0.435 & -0.0078 & 0.501 & 1.70 \\
$\frac{1}{100} \ldots$ & 30.35 & 1.021 & 0.539 & -0.0104 & 0.535 & 1.91 \\
\hline
\end{tabular}


$\theta=-135, \quad t=138$.

\begin{tabular}{|c|c|c|c|c|c|c|}
\hline$v$. & $p$. & $c_{p}$ & $\frac{\partial p}{\partial \theta}$ & $\frac{\partial \eta}{\partial p}$ & $c_{v}$ & $\frac{c_{p}}{c_{v}}$ \\
\hline$\frac{1}{10} \ldots \ldots$ & 4.85 & 0.281 & 0.038 & -0.0051 & 0.200 & 1.41 \\
$\frac{1}{20} \ldots \ldots$ & 9.26 & 0.330 & 0.032 & -0.0051 & 0.227 & 1.45 \\
$\frac{1}{30} \ldots \ldots$ & 13.29 & 0.382 & 0.131 & -0.0051 & 0.254 & 1.50 \\
$\frac{1}{50} \ldots \ldots$ & 20.35 & 0.490 & 0.234 & -0.0055 & 0.313 & 1.56 \\
$\frac{1}{60} \ldots \ldots$ & 23.40 & 0.546 & 0.295 & -0.0054 & 0.334 & 1.64 \\
$\frac{1}{80} \ldots \ldots$ & 28.74 & 0.657 & 0.415 & -0.0066 & 0.361 & 1.82 \\
\hline$\frac{1}{100} \cdots$ & 32.90 & 0.785 & 0.530 & -0.0080 & 0.388 & 2.02 \\
\hline
\end{tabular}

$$
\theta=-130, \quad t=143 .
$$

\begin{tabular}{|c|c|c|c|c|c|c|}
\hline$v$. & $p$ & $c_{p}$. & $\frac{\partial p}{\partial \theta}$. & $\frac{\partial \eta}{\partial p}$ & $c_{v}$ & $\frac{c_{p}}{c_{v}}$ \\
\hline$\frac{1}{10} \ldots \ldots$ & $5 \cdot 055$ & $0.26 \overline{5}$ & 0.0385 & -0.0043 & $0 \cdot 183$ & $1 \cdot 45$ \\
\hline$\frac{1}{20} \ldots \ldots$ & $9 \cdot 71$ & 0.299 & $0-081$ & -0.0043 & 0.201 & $1 \cdot 49$ \\
\hline$\frac{1}{30} \ldots \ldots$ & $14 \cdot 00$ & 0.337 & $0 \cdot 1276$ & -0.0043 & 0.220 & $1 \cdot \overline{5} 3$ \\
\hline$\frac{1}{50} \cdots$ & 2165 & $0 \cdot 416$ & $0 \cdot 2275$ & -0.0045 & 0.259 & J' 61 \\
\hline$\frac{1}{60} \cdots \ldots$ & 25.08 & 0.458 & 0.287 & -00047 & $0 \cdot 270$ & 1.70 \\
\hline$\frac{1}{80} \cdots \cdots$ & 31.03 & 0.556 & $0 \cdot 400$ & -0.0056 & $0 \cdot 306$ & 1.82 \\
\hline$\frac{1}{100} \cdots$ & 35.90 & 0.694 & 0.521 & -0.0062 & $0 \cdot 366$ & 1.89 \\
\hline
\end{tabular}




$$
\theta=-103 \cdot 5, \quad t=169 \cdot 5 .
$$

\begin{tabular}{|c|c|c|c|c|c|c|}
\hline v. & $p$. & $c_{p}$ & $\frac{\partial p}{\partial \theta}$ & $\frac{\partial \eta}{\partial p}$ & $c_{\boldsymbol{v}}$ & $\frac{c_{B}}{c_{0}}$ \\
\hline$\frac{1}{10}$. & 6.065 & $0 \cdot 249$ & 00376 & -0.0027 & $1 \cdot 173$ & $1 \cdot 44$ \\
\hline$\frac{1}{20} \ldots$ & $11 \cdot 82$ & $0 \cdot 264$ & 0.077 & -0.0027 & $0 \cdot 180$ & 1.47 \\
\hline$\frac{1}{30}$. & $17 \cdot 28$ & 0.278 & 0.121 & -0.0027 & $0 \cdot 181$ & 1.54 \\
\hline$\frac{1}{50} \ldots$ & $27 \cdot 40$ & 0.305 & 0.213 & -0.0027 & $0 \cdot 186$ & 1.64 \\
\hline$\frac{1}{60} \ldots$ & $32 \cdot 10$ & 0.320 & 0.265 & -0.0028 & 0.185 & 1.73 \\
\hline$\frac{1}{80} \ldots$ & 40.88 & 0315 & 0.364 & -0.0027 & $0 \cdot 189$ & 1.83 \\
\hline$\frac{1}{i(100}$ & 48.75 & 0.871 & $0 \cdot 491$ & -0.0027 & $0 \cdot 172$ & $2 \cdot 16^{\circ}$ \\
\hline
\end{tabular}

$\theta=-78 \cdot 5, \quad t=194 \cdot 5$.

\begin{tabular}{|c|c|c|c|c|c|c|}
\hline$v$. & $p$. & $c_{p .}$ & $\frac{\partial p}{\partial \theta}$ & $\frac{\partial \eta}{\partial p}$ & $c_{v .}$ & $\frac{c_{p}}{c_{v}}$ \\
\cline { 1 - 5 }$\frac{1}{10} \ldots . .$. & 7.005 & 0.246 & 0.037 & -0.0019 & 0.174 & 1.42 \\
$\frac{1}{20} \ldots \ldots$. & 13.76 & 0.256 & 0.076 & -0.0019 & 0.177 & $1 \cdot 45$ \\
$\frac{1}{30} \ldots .$. & 20.30 & 0.266 & 0.118 & -0.0018 & 0.178 & 1.50 \\
$\frac{1}{50} \ldots . .$. & 32.75 & 0.286 & 0.208 & -0.0018 & 0.181 & 1.58 \\
$\frac{1}{60} \ldots . .$. & 38.65 & 0.295 & 0.257 & -0.0017 & 0.180 & 1.64 \\
$\frac{1}{80} \ldots . .$. & 50.06 & 0.316 & 0.354 & -0.0016 & 0.187 & 1.69 \\
$\frac{1}{100} \ldots$ & 60.80 & 0.339 & 0.473 & -0.0016 & 0.184 & 1.84 \\
\hline
\end{tabular}


$\theta=-35, \quad t=238$.

\begin{tabular}{|c|c|c|c|c|c|c|}
\hline$v$. & $p$. & $c_{p .}$ & $\frac{\partial p}{\partial \theta}$. & $\frac{\partial \eta}{\partial p}$. & $c_{v}$ & $\frac{c_{p}}{c_{v}}$ \\
\hline$\frac{1}{10} \ldots \ldots$ & 8.640 & 0.242 & 0.037 & -0.0010 & 0.171 & 1.42 \\
$\frac{1}{20} \ldots \ldots$ & $17 \cdot 12$ & 0.248 & 0.075 & -0.0009 & 0.174 & 1.43 \\
$\frac{1}{30} \ldots \ldots$ & 25.44 & 0.255 & 0.116 & -0.0009 & 0.174 & 1.46 \\
$\frac{1}{50} \ldots \ldots$ & 41.74 & 0.270 & 0.204 & -0.0008 & 0.178 & 1.52 \\
$\frac{1}{60} \ldots \ldots$ & 49.70 & 0.278 & 0.250 & -0.0007 & 0.181 & 1.54 \\
$\frac{1}{80} \ldots \ldots$ & 65.50 & 0.294 & 0.342 & -0.0006 & 0.190 & 1.55 \\
$\frac{1}{100} \ldots \ldots$ & 81.00 & 0.310 & 0.455 & -0.0005 & 0.190 & 1.63 \\
\hline
\end{tabular}

$\theta=0, \quad t=273$.

\begin{tabular}{|c|c|c|c|c|c|c|}
\hline$v$ & $p$. & $c_{p}$ & $\frac{\partial p}{\partial \theta}$ & $\frac{\partial \eta}{\partial p}$. & $c_{\mathrm{v}}$ & $\frac{c_{p}}{c_{o}}$ \\
\hline$\frac{1}{10} \ldots$ & $9 \cdot 949$ & 0.241 & 0.037 & -0.00051 & $0 \cdot 170$ & $1 \cdot 42$ \\
\hline$\frac{1}{20} \ldots$. & $19 \cdot 80$ & $0 \cdot 245$ & 0.075 & -0.00051 & $0 \cdot 172$ & $1 \cdot 43$ \\
\hline 1 & $29 \cdot 54$ & 0.250 & $0 \cdot 115$ & -0.00050 & $0 \cdot 173$ & 1.44 \\
\hline $30 \cdots$ & & & & & & \\
\hline$\frac{1}{50} \ldots$. & 4878 & 0.259 & $0 \cdot 203$ & -0.00036 & $0 \cdot 171$ & 1.52 \\
\hline$\frac{1}{60} \cdots$ & $58 \cdot 33$ & $0 \cdot 264$ & 0.244 & -0.00025 & $0 \cdot 175$ & 1.51 \\
\hline$\frac{1}{80} \ldots \ldots$ & $77 \cdot 52$ & 0.272 & $0 \cdot 3+2$ & -0.00010 & $0 \cdot 175$ & 1.56 \\
\hline$\frac{1}{100}$ & $96 \cdot 80$ & $0 \cdot 282$ & 0.446 & 0 & $0 \cdot 177$ & $1 \cdot 60$ \\
\hline
\end{tabular}

$\S 15$. These results prove conclusively that the speciric heat at constant volume is a variable quantity. For increasing pressure the quantity $c_{v}$ increases at all temperatures, the more so the lower the temperature. For small pressures the corresponding isothermals converge approximately to the value $0 \cdot 169$, which is the specific heat of air of ordinary density. 
To obtain a graphical representation of the variations of $c_{v}$ I constructed isothermals of that quantity, considering it at first as a function of the density $\frac{1}{v}$. These lines are curves, turning their concave sides to the axis of abscissæ. Afterwards I made the remark that a far simpler law results when $c_{v}$ is considered as a function of the pressure $p$. As shown in fig. 5 the isothermals of $c_{v}$ drawn on that supposition are

Fig. 5.

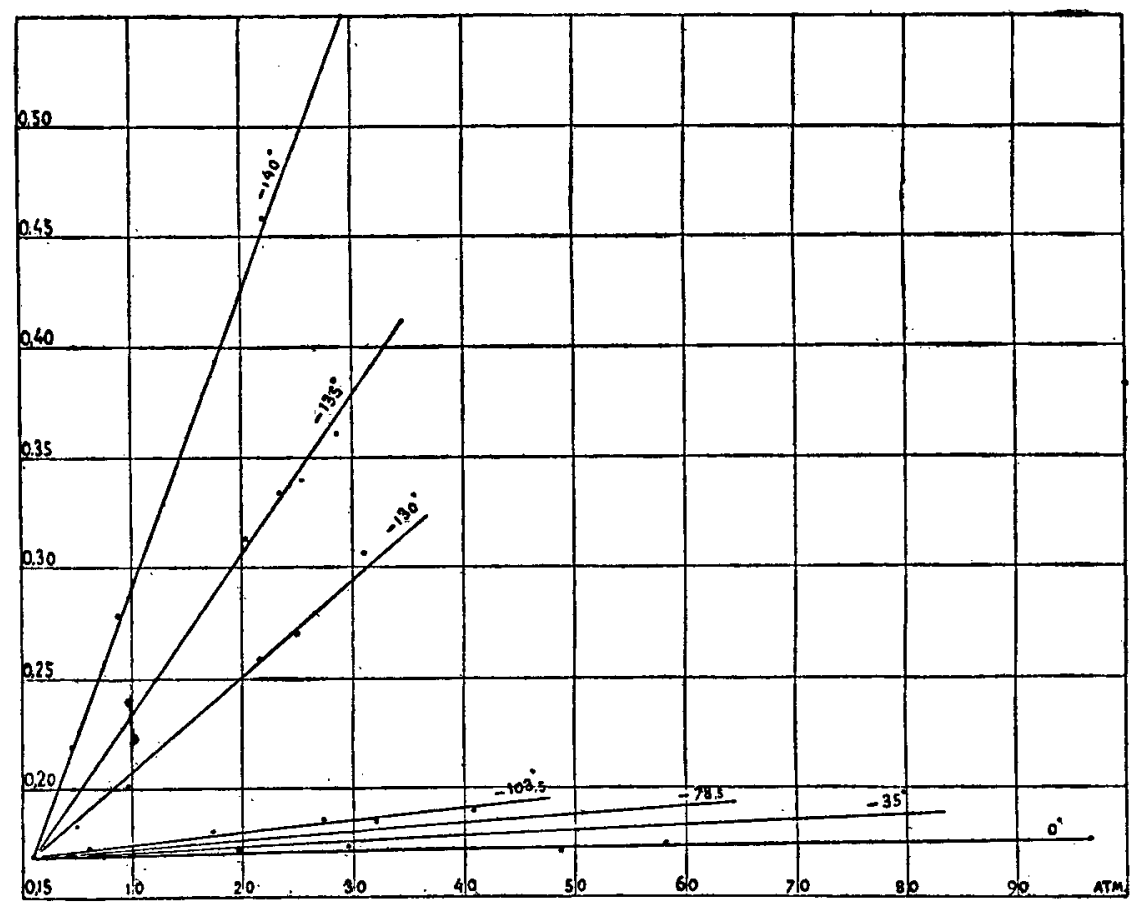

very nearly straight lines. This means that the increments of the specific heat at constant volume are proportional to the increments of pressure caused by increased density, temperature being kept constant. This empirical relation bolds at all temperatures between $0^{\circ}$ and $-140^{\circ}$, and for all densities up to the bundredfold of the ordinary density.

According to this diagram it is possible to express the values of $c_{0}$ between the just mentioned limits by the following linear equations :-

Phil. Mag. S. 5. Vol. 42. No. 254. July 1896. D 


$$
\begin{aligned}
& \theta=-140^{\circ}, \quad c_{v}=0.169+0.0135(p-1), \\
& \theta=-135^{\circ}, \quad c_{v}=0 \cdot 169+0.00722(p-1), \\
& \theta=-130^{\circ}, \quad c_{v}=0 \cdot 169+0.00432(p-1), \\
& \theta=-103^{2} \cdot 5, c_{i}=0 \cdot 169+0.00056(p-1), \\
& \theta=-78^{\circ} \cdot 5, c_{v}=0.169+0.00038(p-1), \\
& \theta=-35^{\circ}, \quad c_{v}=0.169+0.00024(p-1), \\
& \theta=\quad 0^{\circ}, \quad c_{v}=0.169+0.00008(p-1) .
\end{aligned}
$$

As regards the fact of the specific heat at constant volume increasing with increasing pressure, these results are in perfect accord with the direct determinations of Prol. Joly. A numerical comparison cannot be made properly, because these experiments have been performed at higher temperatures $\left(+50^{\circ}\right.$ in the mean). Yet the following result of Prof. Joly may be quoted $(l . c$. page 99$)$. The specific heat at constant volume of compressed air, of absolute density $=00205$ (which corresponds to a pressure of about 19.51 atmospheres), has been found $=0.172 \mathrm{l}$; from the same experiments it is concluded, that the value of $c_{v}$ under atmospheric pressure would be $0 \cdot 17154$. From these numbers there results an increase of $c_{v}$, per atmosphere

$$
=(0 \cdot 1721-0 \cdot 17154): 18 \cdot 51=0 \cdot 00003 .
$$

Considering the difference of temperatures, this agrees well with my own results.

Prof. Joly has also investigated the influence of the temperature on the specific heat $c_{v}$ of compressed gases. For carbonic acid of absolute density 0.124 he finds $c_{v}=0.1971$ at $+50^{\circ}$, and $e_{v}=0.1894$ at $+90^{\circ}$; this means an increase of specific heat at low temperatures. He remarks also, that under small pressures the influence of the temperature is quite insensible. All these conclusions are in perfect agreement with what has been said above with regard to the specific heat of air.

$\S 16$. By means of the results arrived at in $\S 14$ we may now calculate the ratio $k=\frac{c_{p}}{c_{v}}$ of the two specific heats; the values of $k$ are given in the tables of $\S 14$ in the last column. The general features of the variations of $k$ will be best understood if we consider $k$ as a function of the temperature, at constant volume, or at constant density. The corresponding curves are shown in fig. 6 .

With regard to the variability of $k$ our knowledge is exceedingly scanty. The only fact known till now in this respect 
is the experimental result of Wüllner, that the ratio $k$ increases slightly with decreasing temperature (from $1 \cdot 40289$ at $+100^{\circ}$ to 1.40526 at $0^{\circ}$, for air of ordinary density). An increase of

Fig. 6.

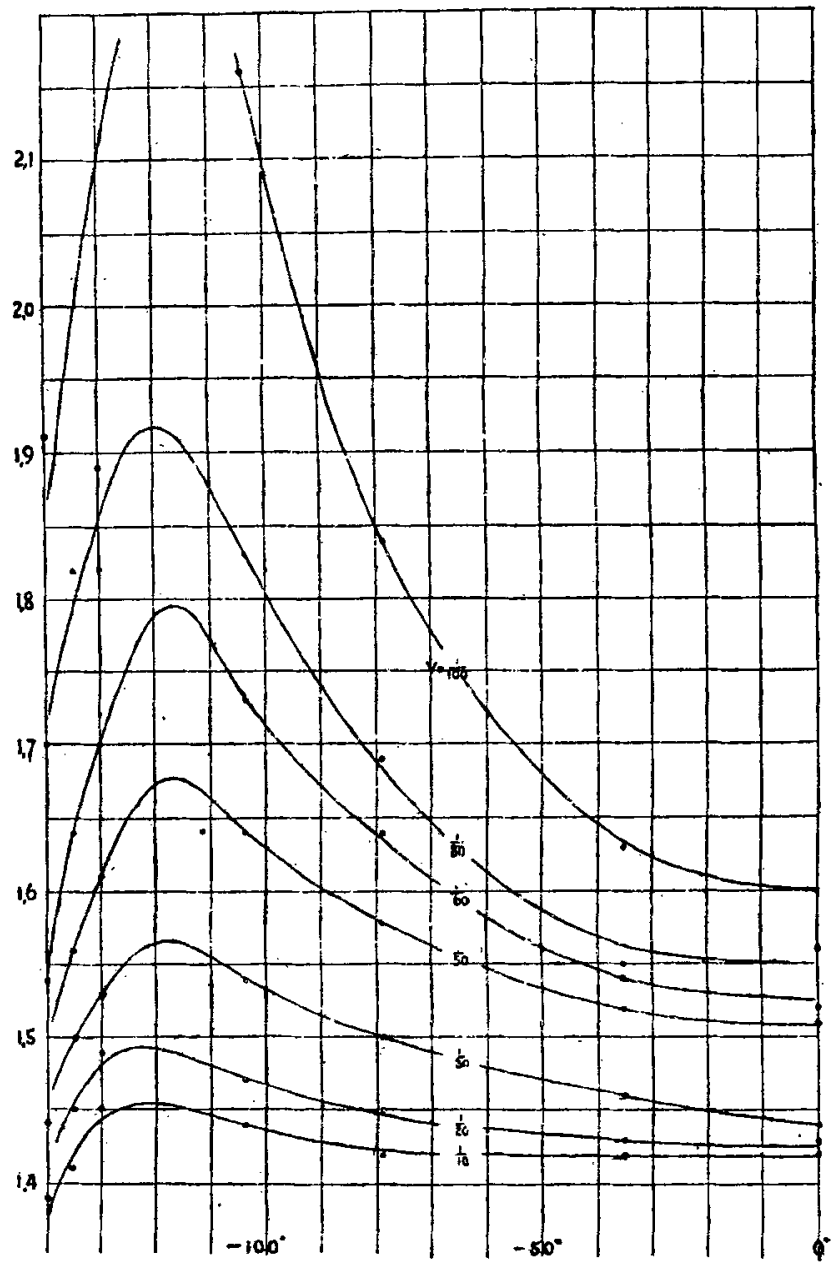

this kind is also shown by the curves of fig. 6. But, moreover, it follows, that with decreasing temperature $k$ reaches a maximum value, which is followed by an abrupt fall. At all densities for which $k$ has been calculated the maximum of D 2 
$k$ corresponds to a temperature of about $-120^{\circ}$. At ordinary temperatures the temperature-variations of $k$ are exceedingly minute, for all degrees of condensation of the gas. At temperatures approaching the critical the increments of the ratio are the more marked the greater the density; in the critical state $k$ is infinite.

With the aid of the diagram (fig. 6) the following table of values of $c_{p}: c_{v}$ has been prepared :-

\begin{tabular}{|c|c|c|c|c|c|c|c|}
\hline$\frac{1}{v}=$ & 10. & 20. & 30. & 60. & 60. & 80. & 100. \\
\hline$\theta$. & \multicolumn{7}{|c|}{ Values of $c_{p}: c_{v}}$. \\
\hline 0 & 1.42 & 1.43 & 1.44 & 1.51 & 1.53 & 1.55 & 1.60 \\
-20 & 1.42 & 1.43 & 1.45 & 1.51 & 1.53 & 1.55 & 1.61 \\
-40 & 1.42 & 1.43 & 1.46 & 1.53 & 1.55 & 1.57 & 1.65 \\
-60 & 1.42 & 1.44 & 1.49 & 1.55 & 1.58 & 1.61 & 1.72 \\
-80 & 1.42 & 1.45 & 1.50 & 1.58 & 1.64 & 1.69 & 1.85 \\
-100 & 1.44 & 1.47 & 1.53 & 1.63 & 1.71 & 1.80 & 2.10 \\
-120 & 1.45 & 1.49 & 1.56 & 1.67 & 1.79 & 1.92 & 1.80 \\
-140 & 1.38 & 1.41 & 1.46 & 1.50 & 1.54 & 1.70 & 1.80 \\
\hline
\end{tabular}

Although the general course of the curves of $k$ is very clearly marked, yet some irregularities manifest themselves in the diagram of fig. 6, chiefly at the highest and lowest temperatures, where the graphical calculation has been also less certain. I have not attempted to correct them arbitrarily, but I drew the curves as near as possible along the calculated points (marked on the diagram by dots).

$\S 17$. In concluding I wish to state expressly thit the absolute numerical values of the several thermodynamic quantities given in $\$ \S 12,14$, and 16 , being obtained by a graphical method of calculation, cannot claim a degree of exactness comparable with that of direct experimental results. Notwithstanding this I considered it useful to spare neither time nor trouble to obtain them, in order to throw some light on these important and wholly unexplored relations.

Wuring the preparation of the manuscript of the present paper I became acquainted with a memoir of Sgr. Silvio Lussano (Nuovo Cimento, 1894, ser. iii. tom. xxxvi. pp. 1, 70, 130 ; 1895 , ser. ii. tom. ii., p. 327 ; " Sul calore specifico dei gas") on the influence of pressure and temperature on the specific heat of gases at constant pressure. The results of Sgr. Lussano, being obtained at higher temperatures, are not 
Melting-points of Aluminium, Silver, Gold, Copper, \&c. 37

directly comparable with mine. As regards the influence of pressure Sgr. Lussano finds, in the limits of pressures employed, an increase of $c_{p}$ with increasing pressure; but the influence of the temperature is just contrary to that which I have found at low temperatures. It cannot be doubted that at sufficiently low temperatures the specific heat $c_{p}$ increases with decreasing temperature, since in the critical state its value is positive infinity. This point must therefore be reserved for further researches, the more so, as the increase of $e_{p}$ with increasing temperature, at higher temperatures, has been proved long ago in some gases (carbon dioxide \&c.) without any doubt.

Physicul Laboratory of the Yaghellonian University, Cracow, November, 1895.

II. Melting-points of Aluminium, Silcer, Gold, Copper, and Platinum. By S. W. Holman, with R. R. Lawnence and L. BARR*

THE following melting-points are offered as provisional 1 only, but with the belief that they are more reliable than previous data. The absolute values depend in part upon the assumption of $1072^{\circ} \mathrm{C}$. as the melting-point of pure gold, the recent determination of Holborn and Wien at the Reichsanstalt. Should that datum, however, be shown to require revision, the validity of the present measurements would not be impaired, but new values of the melting-points could be readily computed from them which would be consistent with the better value for gold.

\begin{tabular}{|c|c|c|c|}
\hline $660^{\circ}$ & $\underset{970^{\circ}}{\text { A }}$ & $\stackrel{\mathrm{Au.}}{\left[1072^{\circ} \mathrm{C} .\right]}$ & $\begin{array}{c}\mathrm{Cu}^{\circ} \\
1095^{\circ}\end{array}$ \\
\hline
\end{tabular}

The Pure Metals used were of a high degree of fineness, except unfortunately the platinum.

The gold contained less than 0.01 per cent. total impurities, these being, if any, probably minute traces of silver and platinum. It was obtained as part of a specially prepared lot from the United States Assay Office in New York through the courtesy of Professor H. G. Torrey, upon whose authority the above statement is made. The purity was at least as great as the best "proof" metal used at the United States or London mints.

* From an advance proof of the Proceedings of the American Academy vol. xxxi. (n. s. xxiii.) p. 218, communicated by Prof. Holman. 